\title{
(ค) ViRAL HePATITIS
}

Published by the Viral Hepatitis Prevention Board (VHPB)

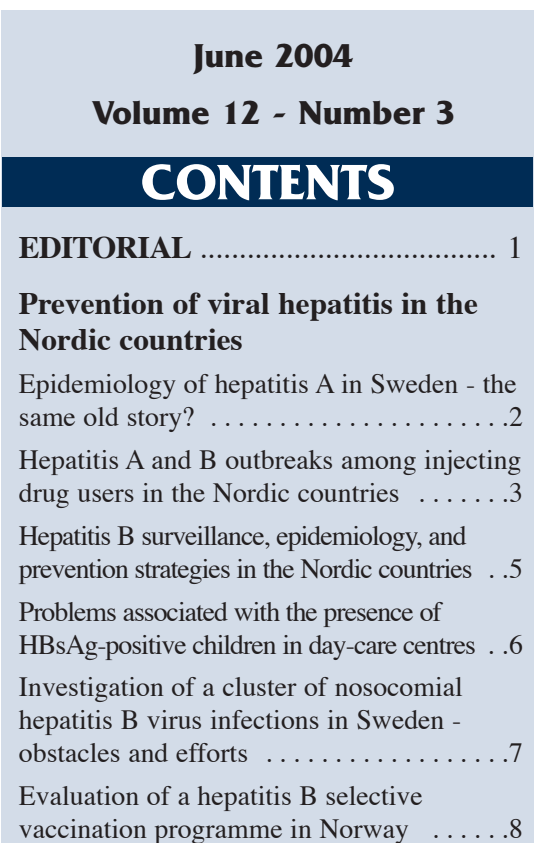

Prevention of viral hepatitis in Germany Organisation of the health-care system in Germany

The German law on prevention and control of communicable diseases (Infektionsschutzgesetz) - surveillance system . . . . . . . . . . . . 10 Epidemiology of hepatitis A in Germany . . .12 Epidemiology of hepatitis B in Germany . . .13 Development of hepatitis B prevention in Germany - the first 10 years . . . . . . . 14 Screening pregnant women for hepatitis B: results from two studies . . . . . . . 15 Groups at risk for hepatitis B infection: who should be vaccinated . . . . . . . . . 17 Universal vaccination against hepatitis B in Germany - a paediatrician's point of view . . .18 Unusual courses of hepatitis B virus infection caused by wild-type virus and escape mutants

Hepatitis C in Germany

Hepatitis $\mathrm{C}$ virus infection in medical settings

Follow-up of iatrogenic hepatitis $\mathrm{C}$ virus infections related to anti-Rh prophylaxis School-entry monitoring of vaccination status

Critical review of programme progress $\ldots .23$

\section{Conclusions of the meeting}

This edition of Viral Hepatitis is based on material presented at the Viral Hepatitis Prevention Board meeting on Prevention of viral hepatitis in the Nordic countries and Germany: lessons learnt and the way forward. Berlin, Germany, October 13-14, 2003.

\section{EDITORIAL}

This issue of Viral Hepatitis examines viral hepatitis prevention and control activities in Germany and the Nordic countries, based on conclusions that were reached during the Viral Hepatitis Prevention Board meeting, held October 13-14, 2003 in Berlin, Germany.

\section{Limitations of selective risk-group immunisation}

One of the key topics for discussion during the Berlin meeting was that of hepatitis B immunisation targeted to risk groups. This policy has been adopted by all of the Nordic countries, based on relatively low hepatitis B virus (HBV) prevalence rates in those regions, but does not comply with the 1992 WHO recommendation that all countries include hepatitis B vaccination in their national universal vaccination programmes by 1997 - recommendations that have been implemented by many other European Union Member States, such as Germany. Besides a risk-group approach, Germany has started implementing universal hepatitis B vaccination programmes for infants, children, and adolescents since 1995.

In view of continuing hepatitis B virus outbreaks, some of which can be traced to nosocomial transmission and clusters of cases among young children in day-care centres, high-risk immunisation strategies will need to be re-examined. Even in areas of low endemicity, between $30 \%$ and $40 \%$ of carriers in industrialised countries acquire HBV infection before the age of five years [1], a situation where selective risk-group immunisation will have no impact and which cannot prevent further transmission among this young group of carriers.

\section{Human and economic costs of HBV infection}

Preventing HBV infection through vaccination is a cost-effective measure in lowendemic countries compared with the measurable costs incurred in health-care interventions for diagnosis, testing, treatment, and contact tracing of HBV infections. Apart from the economic costs are the immeasurable human costs - mortality, chronic disease, and emotional suffering - resulting from vaccine-preventable infections. These statements are fully applicable to the Nordic countries and Germany.

\section{Need for increased cooperation at local levels}

Advocacy and health promotion must also have their place in communicable disease prevention measures. Ideally, these will be carried out in an appropriate social context that will reinforce the credibility of key messages. Working closely with clerics, such as imams, and other influential public figures, can help to enhance the effectiveness of public health information and awareness campaigns, especially when these activities work in synergy with public health authorities, social services, drug treatment centres, prisons, and other public / private partners.

\section{Scientific and industrial innovations}

Combined vaccines have helped to improve acceptance of hepatitis B vaccines and their integration into existing vaccination programmes. The recently developed hexavalent vaccine containing hepatitis B surface antigen has been widely and readily accepted in many countries, particularly in Germany, by paediatricians as well as by parents.

Genome sequencing has proved to be a valuable technique in molecular epidemiology in general and, more specifically, in outbreak management. Considerable progress has also been made in developing safer medical devices such as needle shields and self-blunting needles.

Great progress has been made in the past two decades in prevention and control of HBV infection. In order to maintain this positive trend, there is still much to be done: (1) stricter compliance with international and national recommendations; (2) improved coordination of surveillance networks at national, regional and local levels; (3) continued and improved monitoring systems, including evaluation of programmes; (4) continued and improved outreach programmes to marginalised segments of society; (5) continued information and awareness campaigns through appropriate communication channels at local level; (6) research and development leading to preventive and therapeutic vaccines and medicines, and their accessibility to those in need of these resources.

[1] Mahoney FJ, Lawrence M, Scott C, Le Q, Lambert S, Farley TA. Continuing risk for hepatitis B virus transmission among Southeast Asian infants in Louisiana. Pediatrics 1995; 96:1113-1116.

Johannes Hallauer and Lars Rombo,

on behalf of the Viral Hepatitis Prevention Board 


\section{VIRAL HEPATITIS PREVENTION BOARD}

Core Members

Dr Nedret Emiroğlu

WHO, Regional Office for Europe / EPI

Copenhagen, Denmark

Dr Peter Grob

Clinical Immunology

University Hospital Zürich, Switzerland

Dr Johannes Hallauer

Universitätsklinikum Charité

Berlin, Germany

Dr Mark Kane

Children's Vaccine Program at PATH

Seattle, Washington, USA

Dr André Meheus

Epidemiology and Social Medicine

University of Antwerpen, Belgium

Advisers

Dr Selim Badur

Microbiology Departmen

University of Istanbul, Turkey

Dr Paolo Bonanni

Public Health Department

University of Florence, Italy

Dr José de la Torre

Ministry of Health and Consumers Affairs

Madrid, Spain

Dr Nicole Guérin

Comité Technique Vaccination

Antony, France

Dr Wolfgang Jilg

Institute for Medical Microbiology and Hygiene

University of Regensburg, Germany

Dr Daniel Lavanchy

WHO, Division of Communicable Diseases

Geneva, Switzerland

Dr Harold Margolis

CDC, NCID, Division of Viral Hepatitis

Atlanta, Georgia, USA

Dr Daniel Shouval

Hadassah University Hospital, Liver Unit

Jerusalem, Israel

Honorary Advisers

Dr Pietro Crovari

Institute of Hygien

University of Genoa, Italy

Dr Alain Goudeau

Université de Tours, France

Dr Eric Mast

WHO, Vaccines and Biologicals / EPI

Geneva, Switzerland

Dr Elisabeth McCloy

Dorking, Surrey, United Kingdom

Dr Colette Roure

Direction Générale de la Santé / SD7

Paris, France

Executive Secretary

Dr Pierre Van Damme

Epidemiology and Social Medicine

Enidemiology and Social Medicine

Executive Secretariat

Ms Emmy Engelen

Dr Guido François

Mr Alex Vorsters

Epidemiology and Social Medicine

University of Antwerpen, Belgium

Rapporteurs

Mr David FitzSimons

Geneva, Switzerland

Dr Guido François

Epidemiology and Social Medicine

University of Antwerpen, Belgium

Ms Diana Steimle

Tienen, Belgium
Prevention of viral hepatitis in the Nordic

countries and Germany:

lessons learnt and the way forward

- a VHPB Symposium Report

Berlin, Germany, October 13-14, 2003

\section{Prevention of viral hepatitis in the Nordic countries}

\section{Epidemiology of hepatitis A in Sweden - the same old story?}

\section{Immunity}

Sweden has a relatively long and unique history of recommended hepatitis A prevention measures that have been in place since the 1960s - once even for travellers to Mediterranean countries (e.g., Spain, France, Italy, and Greece). Even short-term travellers to tourist areas were then recommended administration of gamma globulin for prophylaxis of hepatitis A, and compliance was by and large satisfactory.

The unique aspect of the present recommendations, compared with those in other countries, is that they are based on the extremely low proportion of the Swedish population with acquired immunity. Transmission of hepatitis A was, among other reasons, considerably reduced thanks to the early introduction of sewage systems in Sweden, about a century ago. Even as early as the 1970s, only a small minority of the population less than fifty years of age was immune.

\section{Diagnostic possibilities}

Detection of anti-HAV IgM is mandatory for diagnosis in Sweden. RNA fingerprinting has also been carried out during the last ten years during a number of small, Swedish epidemics, some of which can be traced back to injecting drug use, inadequate food hygiene, and travel to endemic areas.

\section{Epidemiology}

Hepatitis A is a notifiable disease in Sweden, with good compliance in reporting icteric patients.

Between 1995 and 1997, an epidemic of hepatitis A infections occurred among injecting drug users (IDUs) and, again, in 1998. These years are, therefore, not representative. Nevertheless, while there is a tendency to fewer cases having occurred between 1997 and 2002, the number of cases as of August 2003 was as high as 100.

\begin{tabular}{|lcccccc|}
\hline Year & 1997 & 1998 & 1999 & 2000 & 2001 & 2002 \\
$\begin{array}{l}\text { Cases acquired } \\
\text { abroad / total cases }\end{array}$ & $112 / 693$ & $73 / 261$ & $105 / 184$ & $57 / 152$ & $69 / 169$ & $44 / 75$ \\
\hline
\end{tabular}

During the last four to six years, the majority of hepatitis A cases were acquired within Sweden. Disregarding the years 1997 and 1998, where epidemics occurred among IDUs, a relatively high number of indigenous cases of hepatitis A were reported between 1999 and 2002. These cases most likely reflect micro-epidemics that occurred in families, nurseries, and other situations where a single patient acquired HAV abroad and transmitted the infection to close contacts in Sweden. These cases are then registered as domestic cases. At the same time, the origin of infection still remains unknown in a substantial proportion of patients. These figures can be used as a powerful argument to persuade travellers to receive the hepatitis A vaccine, and to come back for a second dose after six to twelve months even if they do not plan any further travel at that time.

The table below shows the number of reported HAV infections in Sweden that were acquired abroad. The fact that African countries are entirely absent from the top list (based on number of cases) may reflect Sweden's excellent compliance with national recommendations, and that its long tradition of preventive measures against HAV infection has had a profound influence on travellers, particularly those visiting developing countries. 


\begin{tabular}{|c|c|c|c|c|c|}
\hline \multicolumn{7}{|c|}{ Number of reported HAV infections acquired abroad } \\
\hline 1997 & $\mathbf{1 9 9 8}$ & $\mathbf{1 9 9 9}$ & $\mathbf{2 0 0 0}$ & $\mathbf{2 0 0 1}$ & $\mathbf{2 0 0 1}$ \\
\hline Turkey 12 & Turkey 15 & Turkey 20 & Former Yugoslavia 9 & Spain 9 & Chile 7 \\
Spain 10 & India 5 & Former Yugoslavia 18 & Turkey 4 & Syria 6 & Turkey 6 \\
Ethiopia 6 & Morocco 3 & Syria 10 & Spain 3 & Tunisia 5 & Former Yugoslavia 5 \\
Eritrea 5 & Lebanon 3 & Lebanon 7 & Morocco 3 & Brazil 5 & Iraq 3 \\
USA 5 & Syria 3 & Macedonia 5 & Syria 3 & Pakistan 4 & Greece 3 \\
Lebanon 4 & Russia 3 & Morocco 4 & Tunisia 2 & Dominican Republic 4 & Somalia 2 \\
Russia 4 & United Kingdom 3 & Pakistan 4 & India 2 & Russia 4 & Brazil 2 \\
United Kingdom 4 & Spain 2 & Norway 3 & Bulgaria 2 & Turkey 4 & Tunisia 1 \\
& & & & & \\
\end{tabular}

Nationality, age distribution of HAV-infected patients, and seasonal trends

It has not been possible to establish with certainty the nationality of HAV-infected patients due to data-protection laws in Sweden. For both domestic and foreign transmission, two age-peaks occur, among children between five and nine years of age and among adults between thirty and thirty-nine years of age. Among HAVinfected children foreign transmission exceeds domestic transmission, perhaps when travelling with their parents visiting friends and relatives. In adults the reverse is true, with several explanations possible. One explanation is the number of IDUs classified as domestic transmission. A second explanation is the immunity of parents visiting friends and relatives, who will not become infected and therefore not add to the number classified in the age group above twenty years. A third and similar explanation is transmission of HAV from non-immune non-icteric children in nurseries and other similar living situations to their parents who will then be icteric and diagnosed. It is not known how many children are infected with HAV without notification.

An increasing number of hepatitis A cases are reported in August and September, which reflects the time of the year when Swedish tourists go on annual summer leave. This is also the time when immigrants return to their home country for family visits. Because of Sweden's data-protection laws, it is not possible to distinguish between cases among immigrants or Swedish travellers to endemic areas.

\section{Conclusions}

- The number of cases of hepatitis A in Sweden has been steadily decreasing, apart from outbreaks among IDUs and microepidemics within families. HAV infection is now rare in Sweden and not even primarily suspected in icteric Swedish patients.

- There are very few cases of HAV infection acquired in Africa, which suggests that Swedish travellers to developing countries are well vaccinated before departure.

- Hepatitis A cases acquired abroad can also originate from countries that are not highly endemic.

Based on a presentation by Dr Lars Rombo, Department of Infectious Diseases, Mälarsjukhuset, Eskilstuna, Sweden.

\section{Hepatitis A and B outbreaks among injecting drug users in the Nordic countries}

All of the Nordic countries (with the exception of Iceland) reported hepatitis A and hepatitis B outbreaks among injecting drug users in the 1990s and early 2000s. The largest outbreaks occurred in
Finland and Norway, with moderate outbreaks in Sweden, and the smallest outbreaks in Denmark.

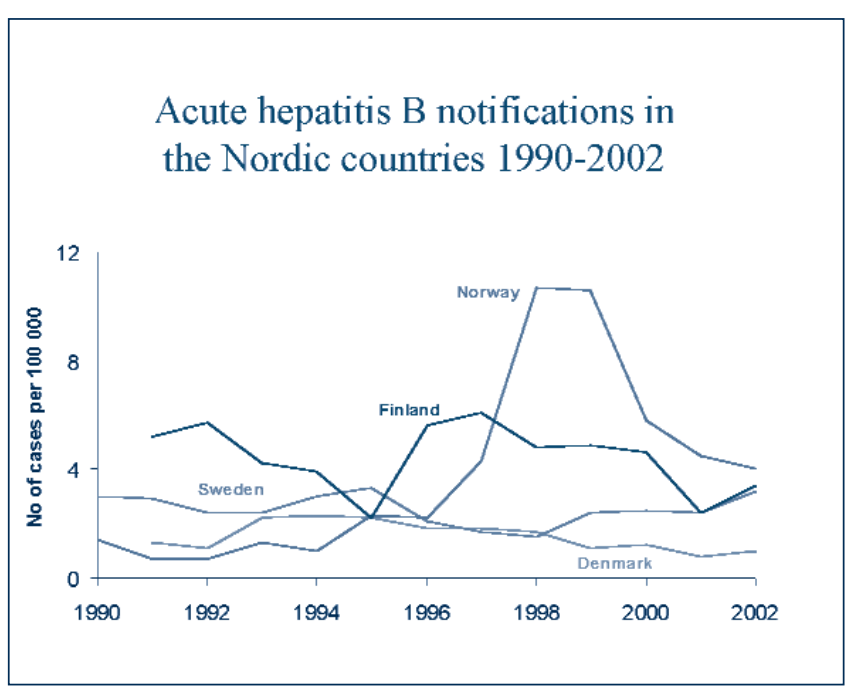

Hepatitis A notifications in the Nordic countries 1990-2002

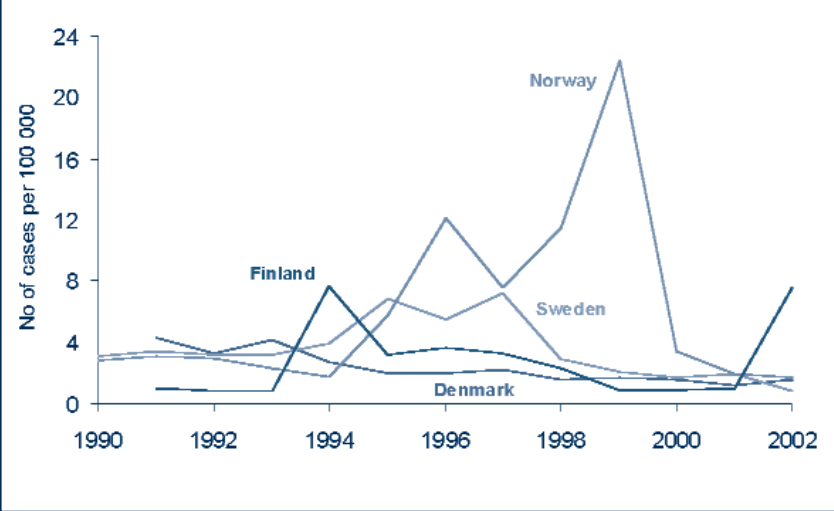


In spite of extensive harm-reduction measures in many countries, such as distribution of free needles and information campaigns on how to rinse tools when injecting drugs, Finland, Norway, and Sweden have experienced large outbreaks of both hepatitis A and hepatitis B among drug users during the 1990s. In addition, $60 \%-80 \%$ of drug users in the Nordic countries have tested positive for hepatitis C antibodies. The main route of transmission for all these types of hepatitis is most likely sharing syringes, needles, and other equipment, although sexual transmission and faecal-oral contact play a role. One of the reasons for these outbreaks is the dramatic increase in non-immune drug users that has been reported over the years in many of the Nordic countries.

No increases in HIV infection (except in Finland) occurred in the 1990s and 2000s. Swedish and Norwegian data for 1992 - 2002 (shown below) illustrate the comparatively low levels of HIV infections during the time when hepatitis A and acute hepatitis B outbreaks were occurring. Drug users are extensively tested for both hepatitis and HIV and this lack of reported cases of HIV infection cannot be explained by less testing for HIV. This difference in the spread of hepatitis and HIV among injecting drug users is hard to explain. Some form of internal rules and conduct within the drug injecting community may however play an important role, i.e. sharing syringes or needles with an HIV-infected drug user is regarded as an unacceptable practice by the drug users themselves. In the case of sharing, the HIV-positive will be the last to use the syringe. This mechanism of HIV prevention can only work if HIV-infected drug users know about their HIV status, and if they are open about it without feeling stigmatised by their fellow drug users. In addition, most drug users are fearful of HIV infection and its consequences. In contrast, hepatitis is much more common and regarded by drug users as a much less severe disease compared with HIV/AIDS. There have been few studies carried out on this behavioural pattern in the Nordic countries, but interviews with drug users indicate that such attitudes exist within the drug communities. Other explanations can of course be the lower transmission rate of HIV.

IIcpatitis A, acutc hepatitis B, and IIIV infection reported among drug users in Sweden 1992-2002

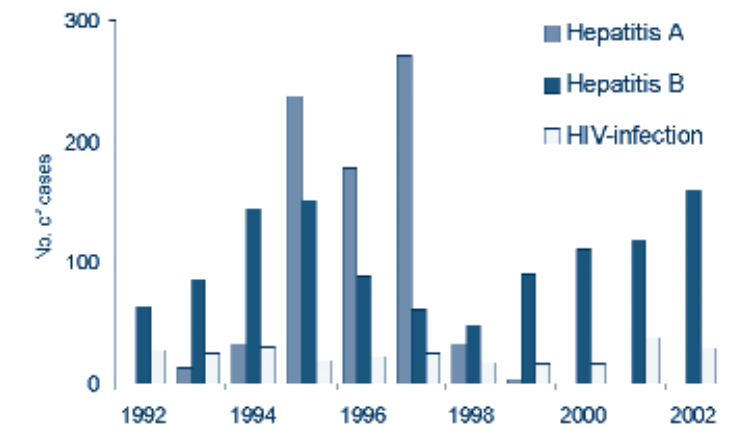

IIcpatitis A, acutc hepatitis B, and IIIV infection reporled among drug users Norway 1992-2002

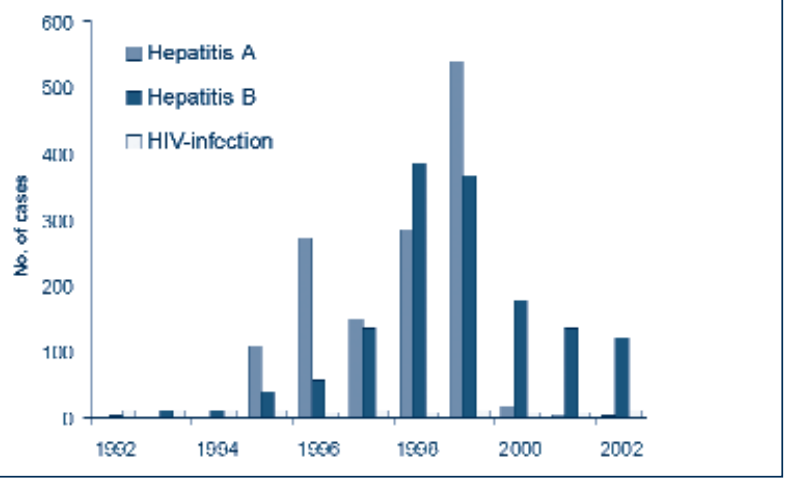

Local prevalence studies among injecting drug users are carried out in all of the Nordic countries. A seroprevalence study carried out among 412 drug users in Oslo in 2001 showed the following:
- HAV IgG
- HBsAg
$60 \%$
- Anti-HBc
$3 \%$
- Anti-HBs and anti-HBc
$53 \%$
- Anti-HCV
$25 \%$
$79 \%$
- Anti-HCV and HCV RNA $47 \%$
- HIV
$1.2 \%$
- HTLV-II
$3.7 \%$

A remarkable feature of the $\mathrm{HBV}$ infection outbreaks in Norway is that they were not confined to large cities, but also occurred in outlying areas of the country. In 2002, only about $6 \%$ of acute hepatitis B cases among drug users were registered in Oslo.

Norwegian hepatitis A and hepatitis B notification data (19922002) show injecting drug use as the main route of transmission. These outbreaks have also resulted in secondary transmission of infections to sexual partners (hepatitis B) and to family contacts (hepatitis A). The main prevention measures to stop these outbreaks have been:

- Cooperation between social services, health authorities, treatment centres, prisons, etc.

- Information to drug communities

- Readily available clean needles and syringes

- Vaccination against hepatitis A and B

Vaccination against hepatitis A and B remains a key primary prevention measure. The success of this strategy will depend on continuing advocacy efforts to encourage acceptance of vaccination among the injecting drug community.

Based on a presentation by Dr Hans Blystad, Department of Infectious Disease Epidemiology, Norwegian Institute of Public Health, Oslo, Norway. 


\section{Hepatitis B surveillance, epidemiology, and prevention strategies in the Nordic countries}

Although hepatitis B is a notifiable disease in all five Nordic countries (Norway, Sweden, Denmark, Finland, and Iceland), policies vary considerably with regard to immunisation recommendations for groups considered at risk for viral hepatitis, reimbursement, and harm-reduction measures.

All of the Nordic countries report both acute and chronic hepatitis, with the exception of Iceland, which makes no differentiation between acute and chronic cases. In 2002, the incidence of acute hepatitis B per 100,000 inhabitants was relatively high in Norway (4.0), Finland (3.4) and Sweden (3.2). The northwest Russian border regions, extending from northern Norway and eastern Finland down to the Baltic countries, have hepatitis B incidence rates between 17.9 and 28.6 per 100,000 inhabitants (figures in 2002).

Incidence of acute hepatitis B per 100000 population in 2002

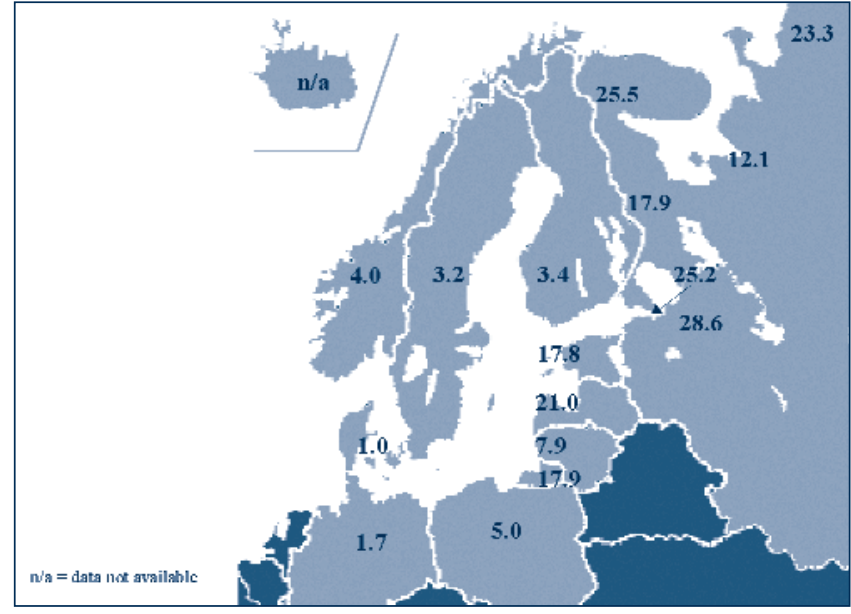

The relatively high acute hepatitis B incidence rates reported in 2002 in most of the Nordic countries and Northwest Russia are mainly caused by outbreaks among injecting drug users and their sexual partners.

\begin{tabular}{|c|c|c|c|c|}
\hline \multicolumn{5}{|c|}{$\begin{array}{c}\text { Acute hepatitis B notifications in the Nordic countries in } 2002 \\
\text { by route of transmission }\end{array}$} \\
\hline Type of transmission & Denmark & Finland & Norway & Sweden \\
\hline Injecting drug users & 11 & 28 & 120 & 166 \\
\hline Sexual transmission & 23 & 42 & 42 & 77 \\
\hline Others / unknown & 29 & 57 & 21 & 46 \\
\hline Total & 63 & 127 & 183 & 289 \\
\hline
\end{tabular}

Between 1995 and 2002, the highest incidence rate for acute hepatitis B was in Norway, attributed mainly to outbreaks occurring among increasing numbers of infected injecting drug users. The lowest number of notified acute hepatitis B cases in Norway was in 1990, with the highest level in 2000.

\section{Hepatitis B prevention measures}

The four main measures for prevention against hepatitis B in the Nordic countries are pre-exposure and post-exposure immunisations, testing in pregnancy, and harm-reduction measures among injecting drug users. While all five countries have selective hepatitis B vaccination, there are differences in terms of targeted risk groups per country and reimbursement policies.

\begin{tabular}{|l|c|c|c|c|c|}
\hline \multicolumn{5}{|c|}{ Hepatitis B prevention in the Nordic countries } \\
- main preventive measures \\
\hline $\begin{array}{l}\text { Prevention } \\
\text { measure }\end{array}$ & Selective & Selective & Selective & Selective & Selective \\
\hline $\begin{array}{l}\text { Pre-exposure } \\
\text { immunisation }\end{array}$ & Selective & Selective & Selective & Selective & Selective \\
\hline $\begin{array}{l}\text { Testing in } \\
\text { pregnancy }\end{array}$ & Ses & Yes & Few & Yes & Few \\
\hline $\begin{array}{l}\text { Harm-reduction } \\
\text { in drug users }\end{array}$ & Yes & Yes & Yes & Yes & Yes \\
\hline $\begin{array}{l}\text { Post-exposure } \\
\text { immunisation }\end{array}$ & Yes & & & & \\
\hline
\end{tabular}

In all of the five countries, injecting drug users are the main group recommended for vaccination, while male homosexuals are a target group in only three of them. Employees in high-risk occupations, like some health-care workers, prison staff, and the police, are regarded as a target group for vaccination in all Nordic countries. Medical students, however, are not covered, as they are not considered officially employed. Most medical conditions warranting hepatitis B vaccination are covered by most of the countries. However, some risk groups, such as dialysis patients, are recommended for vaccination only in Norway and Sweden.

In terms of reimbursements, in Norway, for example, some vaccines are free with costs covered by the State; others are free depending on the regional authorities; and some are partially free or paid by employers. Norway also has one of the most extensive immunisation programmes for immigrants from high-endemic areas, including their newborns.

\section{Harm-reduction measures among injecting drug users}

All Nordic countries have pursued a restrictive drug policy, banning possession, use, and trafficking of drugs. The Nordic countries have all strongly resisted any liberalisation or decriminalisation. The goal remains a drug-free society. Measures to reduce demand and supply of drugs are therefore still the basis of the prevention strategy in all Nordic countries. The question of harm-reduction measures is more controversial. Harm-reduction measures aim at reducing the damaging effects of drug use (like HIV infection and hepatitis) to the users themselves, their family, and society.

While extensive free-needle or needle-exchange programmes, or both, are in use in Norway, Denmark, and Finland, this is not generally the case in Sweden or Iceland. Clean needles and syringes are, however, available at pharmacies in all of the countries. In Sweden, syringes can only be obtained by prescription from a doctor. Likewise, Sweden is more restrictive in offering drug-assisted treatment (like methadone and buprenorfin) than the other countries. In Oslo, more than 1.5 million syringes and needles are distributed free of charge each year. This must be 
compared with the less than 400,000 distributed in Copenhagen each year. However, the huge number of free syringes offered to drug users in Oslo has raised some serious questions about possible harmful effects. Oslo is the city with the highest relative number of drug-related deaths (mostly due to an overdose) in western Europe and the number of deaths has increased sharply during the 1990s. This increase in mortality has no simple explanation, but it could be related to a more widespread drug injecting culture in Oslo compared with other European countries, where smoking heroine is much more common. Easy access to syringes may promote injection practice. As a consequence of this high mortality rate, public injecting rooms supervised by health personnel will most likely be established next year in some Norwegian cities. This harm-reduction measure is highly controversial in Norway.

\section{Summary}

- Hepatitis B notification data are accurate for all Nordic countries (except Iceland) for both acute and chronic disease.
- There has been an increased incidence in hepatitis B in all Nordic countries coinciding with an increase in the number of injecting drug users during the 1990s and early 2000.

- Hepatitis B outbreaks continue to occur and may be attributed to injecting drug users.

- All Nordic countries have selective hepatitis B vaccination, but there are striking disparities in risk-group recommendations due to different health structures, reimbursement policies, or possibly even historical reasons.

- The various harm-reduction strategies in the Nordic countries do not reflect the incidence of HBV or HIV infections among injecting drug users.

Based on a presentation by Dr Hans Blystad, Norwegian Department of Infectious Disease Epidemiology, Institute of Public Health, Oslo, Norway.

\section{Problems associated with the presence of HBsAg-positive children in day-care centres}

Sweden's 1991 recommendations concerning HBsAg-positive children in day care are vague and ambiguous, and have resulted in a lack of consensus among the twenty-one counties on how the recommendations are to be interpreted and implemented.

The issue of vaccination is particularly unclear for age groups three to five years as well as for children five years and older:

In a Swedish study of HBsAg-positive children in day-care centres, carried out between 1991 and 2002, thirty-three acute hepatitis B cases were reported [1], of which six of the children were infected in Sweden - three of foreign origin, and three of Swedish origin. While these numbers are relatively small, they reflect a larger problem regarding potential spread of infection through family and other close contacts, particularly in communities having an immigrant population from endemic areas, and where Swedish epidemiological data are lacking.

Obtaining informed consent for vaccination from parents of at-risk children required extensive time and preparation by medical professionals involving at least two meetings with the parents of each of the thirty children, with an estimated round-trip travel time of four hours and financial costs covering the salaries of one to two medical staff. In financial terms this amounted to approximately 110,000 Swedish crowns before vaccination even started or the equivalent of enough vaccine doses for more than 200 children.

Comments and questions that were obtained from staff and parents during follow-up meetings revealed a serious lack of knowledge about hepatitis B and the vaccine. While there is anonymity regarding carriers, parents raised questions that reflected a wide range of opinions and level of knowledge:
- If a new (foreign) child is introduced in the day-care centre who can it be?

- Why vaccinate my child?

- Why not vaccinate our entire group as the children all play together?

- Should neighbours and relatives also be vaccinated?

- Is the vaccine effective?

- Is the vaccine safe?

- Why no test for antibodies? How can you know that my child is not a non-responder?

\section{Conclusions}

Available data and the experience of J. Struwe illustrate the need for a universal hepatitis B immunisation programme in Sweden, where all children regardless of ethnic background benefit from hepatitis B prevention. Further options include screening pregnant women and refugees, and vaccination of injecting drug users and household contacts of carriers. The worst possible option is for Sweden to maintain its present recommendations, which are not in keeping with prevention measures that have been adopted in most European Union Member States, and with the WHO recommendation to include hepatitis $\mathrm{B}$ vaccine in childhood vaccination schedules.

\section{References}

[1] Data from Ragnhild Janzon, Swedish National Institute for Infection Control.

Based on a presentation by Dr Johan Struwe, Karolinska Institute, Department of Infectious Diseases and Infection Control, Karolinska University Hospital, Huddinge, Sweden. 


\section{Investigation of a cluster of nosocomial hepatitis B virus infections in Sweden - obstacles and efforts}

Nosocomial transmission of HBV is rare in Sweden. Data from the Swedish National Institute for Infection Control show a dramatic decrease since 1985 of HBV infections in staff from medical, dental, laboratory, and other related settings.

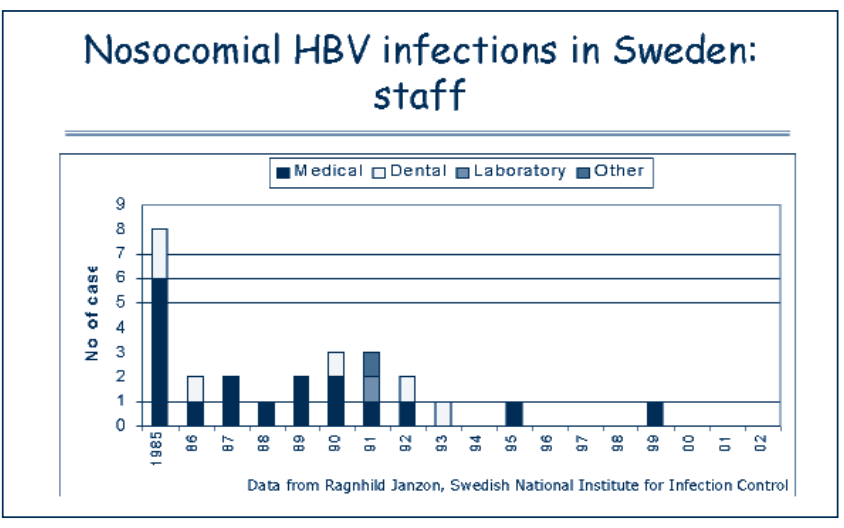

The number of cases of nosocomial HBV infections among patients in Sweden decreased from twelve cases between 1991 and 1996 to five cases between 1997 and 2002. Nonetheless, investigation of a cluster of five cases in southern Stockholm incurred high costs:

- at a human level

- development of chronic infection and cirrhosis

- further transmission to spouse

- loss of life

- at a financial level

- treatment of the HBV-infected patients

- contact tracing

- investigation into the outbreak sources

- preventing further transmission to staff and other patients

The first four of these cases of $\mathrm{HBV}$ infections at Huddinge University Hospital were reported between 1999 and 2000; the fifth case occurred in 2002. The immediate course of action was to identify the source of infection in each of the patients to avoid further transmission. The possible infection sources that were taken into consideration, case by case, were as follows:

Case \# 1 in November 1999, involving a 75 year-old male, endstage renal disease, recent shift from PD to HD after peritonitis - A known HBV-positive dialysis patient?

- Contaminated blood?

- Unrecognised dialysis-/other patient?

Case \# 2 in March 2000, involving a 34 year-old male with Burkitt lymphoma

- Same blood donor as case \# 1?

- Thai wife?

- Unrecognised patient in haematology?

Case \# 3 in August 2000, involving a 57 year-old male with coronary heart disease

- No blood transfusion

- No treatment in the same clinics as cases \# 1 and 2

- Isolated case?

Case \# 4 in August 2000, involving an 18 year-old male with malignant lymphoma
- Treated at same clinic as case \# 2 during overlapping period; however, not even blood sampling was carried out on the same day

- Same blood donor as case \# 1 and/or case \# 2?

In order to identify the infection source, the following steps were taken:

- Regular contact tracing among sexual partners, family members, etc.

- Ruling out common blood donors

- Identifying seroconverted blood donors

- Identifying HBV DNA-positive dialysis patients

- Sequencing HBV DNA-positive cases and possible sources

There was also intensified surveillance of dialysis patients in order to identify any new cases, and prevention measures were put into place through immunisation of unvaccinated hospital staff and review of infection control practices.

The outcome of the source investigations regarding the four mentioned cases of HBV infection in 1999-2000 revealed:

- Thai wife (case number 2) was HBsAg-positive (other spouses were negative), but she turned out to be anti-HBc IgM-positive and thus a secondary case

- No common blood donor

- 3/4 of HBsAg-positive dialysis patients were HBV DNApositive

- All 8 anti-HBc-positive dialysis patients were anti-HBc IgMand HBV DNA- negative

It was possible to conclude from sequencing that there were two coupled pairs (with one secondary case), and one isolated case of infection. Molecular typing was useful for confirmation of related cases as well as for excluding non-related cases and a common source.

In February 2002, a fifth case of nosocomial HBV infection occurred in a 47 year-old male patient with acute lymphoblastic leukaemia (ALL), who was seronegative in 2000, and in 2002 had active chronic HBV infection. This patient, however, had an entirely different subtype of HBV.

For the five HBV-infected patients, the consequences resulted in:

- one death from liver failure

- one case of chronic infection and cirrhosis within five years

- one case of transmission to spouse

- emotional pain caused by not knowing the source of infection

- one death from underlying disease

- chronic infection that cleared after cessation of immunosuppression.

Total measurable costs (in Swedish crowns)
Treatment

Investigation of outbreak

Contact tracing

Vaccination
157.000

40.000

362.000

113.000
= vaccine cost for some 1200 infants with monovalent hepatitis B vaccine! 
Further assessment revealed that there were additional prevention measures that were not implemented:

- Dialysis patients were only tested twice

- Dialysis patients were not vaccinated

- Only 132 out of 209 blood donors had been tested

Furthermore, $50 \%$ of hospital staff reporting injuries from needlesticks and sharps are still unvaccinated against HBV infection. These figures point to obvious areas for improvement in preventing nosocomial HBV infections in hospital settings, and suggest that hepatitis B vaccination should be mandatory for persons at occupational risk of HBV infection.

Based on a presentation by Dr Johan Struwe, Karolinska Institute, Department of Infectious Diseases and Infection Control, Karolinska University Hospital, Huddinge, Sweden. We are greatly indebted to Professors Lars Magnius, SMI (who performed HBV sequencing), Per Ljungman, and Carl-Gustaf Elinder.

\section{Evaluation of a hepatitis B selective vaccination programme in Norway}

The rationale for Norway's selective hepatitis B vaccination programme is that, despite the number of hepatitis B outbreaks in Norway during the 1990s, the prevalence of HBsAg carriers is low, with very few carriers outside defined risk groups. The philosophy behind Norway's hepatitis B immunisation programme is to protect persons considered at increased risk of HBV infection.

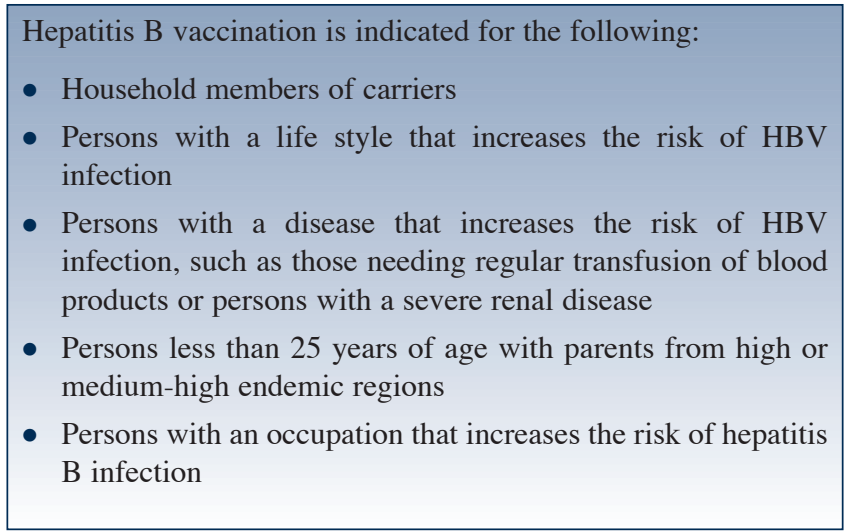

Hepatitis B vaccine is given free of charge to the first four above-mentioned risk groups. As the vaccine must be ordered from the Norwegian Institute of Public Health on a named person prescription basis, it is possible to calculate the number of doses given to each risk group.

\section{Household members of carriers}

Most of the carriers in this group are immigrants from highendemic countries. The number of new carriers depends to a large extent on the political situation, which can have an impact on the number of refugees coming to Norway from particular countries. In 1998 / 1999, a high percentage of persons coming to Norway from Kosovo resulted in an increased number of new carriers.

Persons with a life style that increases the risk of $\mathrm{HBV}$ infection The three main groups that are targeted are:

- Drug users

- About 1000 new drug users are seen each year

- Hepatitis B outbreaks peaking in 1998 / 1999

- Large vaccination campaigns targeting this group were organised in 1999 and 2000.

- Men having sex with men

- Sex workers

Conclusions - drug users

Even this group can be reached through targeted campaigns. In years without special campaigns, the vaccine used is just sufficient to immunise the estimated number of new drug users. As many established drug users are not immunised this is not sufficient to improve the situation.

\section{Children with parents from countries outside} low-endemic areas

The recommendation to immunise all children with parents from countries outside low-endemic areas was first issued in 1992, with priority given to infants and adolescents. This recommendation was issued as a special offer to children with higher risk than normal in Norway. Since 1996, there has been increasing focus on this recommendation and as of 2002 it forms an important component of Norway's vaccination programme.

Approximately 3,000 children in this target group, with at least one parent from an intermediate- or high-endemic country, are born in Norway each year. The total target group varies according to the number of immigrants, and the native country of the immigrant.

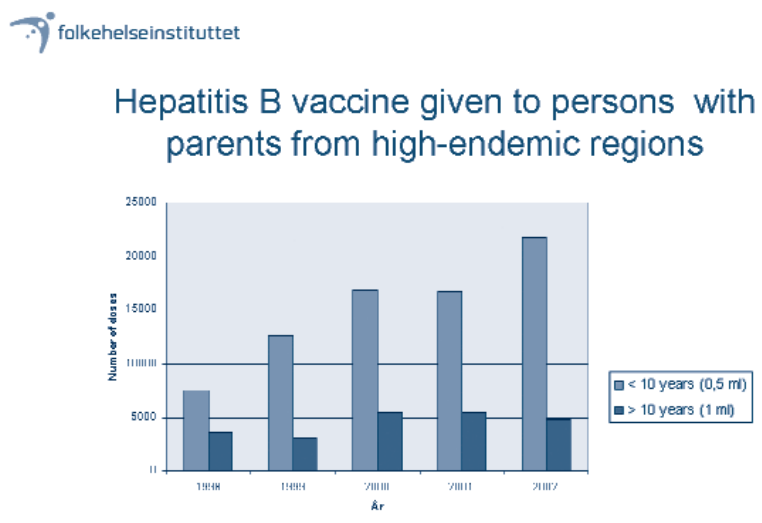

Conclusions - children of immigrants

Prior to 1998 , this programme reached only a small part of the target population. During the last three years, the vaccination coverage has increased from approximately $60 \%$ to about $70 \%$. This shows that a selective programme can cover an acceptable part of the target population, but the impact is difficult to evaluate.

\section{General conclusions}

There is still a need to consider the social / political implications of selective hepatitis B immunisation and not only the economic attractiveness. Eventually immigrants remaining in Norway on a long-term basis will be integrated into the indigenous population, which may have an impact on the hepatitis B prevalence.

Based on a presentation by Dr Hanne Nфkleby, Department of Vaccination and Immunity, Norwegian Institute of Public Health, Oslo, Norway. 


\section{Prevention of viral hepatitis in Germany}

\section{Organisation of the health-care system in Germany}

Germany's health-care system is dominated by a health-insurance scheme in which an individual's benefits are independent of individual contributions, providing nearly all of Germany's citizens with health-care coverage. At the same time, there is also a separate private health-insurance market that reflects the supply and demand for services. Both employers and employees share the financial burden of health-care costs.

This health-care system, while well adapted for Germany one hundred years ago, has become unsustainable in the 21st century. Comparable to what happens in other countries of western Europe recent demographic trends in Germany show an ageing population requiring long-term health care. This, combined with increasingly low birth rates and high levels of unemployment, has led to calls for reform. Further political and public outcries for modernisation followed when the World Health Organization ranked Germany's health system in 1997 number twenty-five among WHO's 192 Member States in terms of overall performance, trailing behind twenty other European countries [1].

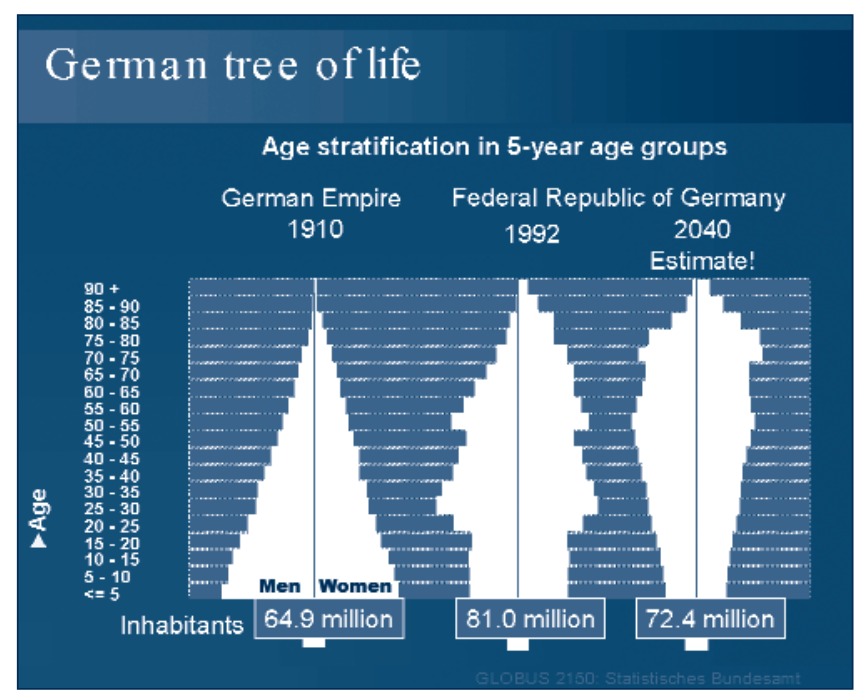

\section{Germany's political structure}

Germany is made up of a federation comprising sixteen States (Länder). Legislation is enacted through the Bundestag (comparable to the United States Congress) that passes bills. The Bundesrat (comparable to the United States Senate) approves the bills that are applicable to the interests of the federal States. Execution and supervision of laws are carried out by three separate administrative units:

- Federal administration, for example:

- Supervision of registration of medicines

- Insurance control

Federal Works Office

- Self administration, for example:

- Physicians' fees

- Setting of medicines' budgets

- State administration, for example: - Licensing of professions

- Fiscal authorities
The State administration, listed above, is made up of a joint commission of sickness funds and the federal association of physicians accredited by the statutory health insurance system. This system is thus operating with health-care purchasers and providers privately managing their own organisations within the public law system. Nearly $90 \%$ of the German population is covered by compulsory health insurance and approximately $10 \%$ is covered by private health insurance.

\section{Germany's social insurance system}

Germany has a social insurance system that has been mandatory since the end of the 19th century, covering statutory health insurance. There are approximately 400 health insurance companies organising and managing the system within the German legal framework. The financial basis of the system is under continual pressure, challenged by the increasing life expectancy of the German population, early retirement, and health insurance coverage for the unemployed and family members. In addition, there is a statutory commitment to pay for $50 \%$ of individual nursing home costs. As the elderly population needing health care continues to rise, in the year 2050 Germany will be faced with 10 million people over the age of sixty-nine (total population 2003: about 82 million).

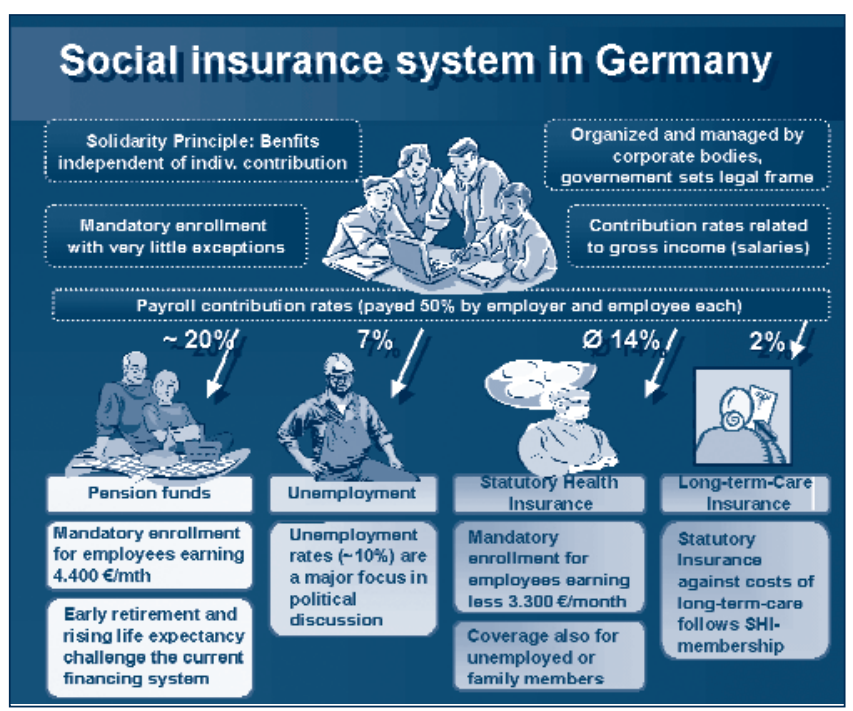

Despite WHO's somewhat low ranking of Germany's health-care system in 2002 (see above), 10.7\% of Germany's gross national product went to health care - the third highest proportion in the world (2600 euro per capita). Hospitals accounted for $45 \%$ of Germany's 218 billion euro health costs, and physicians and medicines another $22 \%$ each. Costs per day in a German hospital were less than one quarter of costs per day in a hospital in the USA. Performance indicators also show that German hospitals were better compared with those in the USA [2,3].

\section{A health-care system lacking synergy}

The various elements of the German health-care system may be compared to a series of silos that often lack interaction or linkage, 
with each of the components being managed independently of one another. The physicians' association and sickness fund associations determine physicians' salaries as well as the budget for medicines with some possibility of a trade-off between the two budgets. The Regional Ministries of Health of the Länder, together with the hospitals and sickness funds determine a separate budget for inpatient care, with budgets for ambulatory care and the hospitals strictly divided. There is still another separate budget for long-term care insurance with no interaction with other components of the system. There are attempts, however, at trying to close some of these gaps to achieve greater synergy among the various elements of the system.

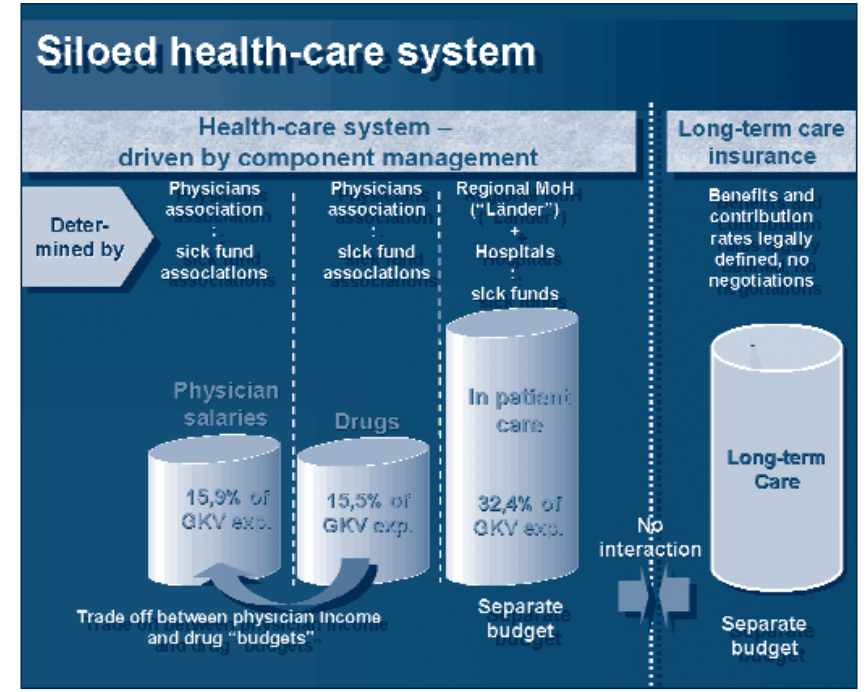

The need for cost-effectiveness of preventive medicine

Currently there is a huge imbalance between expenditures for prevention, which represent only $1 \%$ of total expenditure, and for treatment of infectious diseases. While recommended vaccines are usually paid for out of the sickness fund association budget, and are offered free of charge to members of the fund, the fund is not obliged to provide the vaccines. There is a pressing need to carry out analyses of the cost-effectiveness of preventive interventions that can be used at political levels to redress the imbalance between prevention and treatment.

\section{References}

[1] World Health Organization. The world health report 2000. Health systems: improving performance. Geneva, World Health Organization, 2000.

[2] Wissenschaftliches Institut der AOK (WIdO). KrankenhausReport 2001.

http://www.wido.de/Krankenhaus/Krankenhausreport/Report2001 [3] Centers for Disease Control and Prevention. Health, United States, 2001

http://www.cdc.gov/nchs/products/pubs/pubd/hus/2010/2010.htm\#hus01

Based on a presentation by Dr Johannes Hallauer, Universitätsklinikum Charité, Gesundheitssystemforschung, Berlin, Germany.

\section{The German law on prevention and control of communicable diseases (Infektionsschutzgesetz) - surveillance system}

In January 2001, Germany's Infektionsschutzgesetz (IfSG) or law on prevention and control of communicable diseases came into force. The primary objective of this law is to improve surveillance and reporting of communicable diseases as well as their prevention and control. The Federal Republic of Germany has a complex public health structure with 16 State and about 450 local health departments reporting indirectly or directly to the Robert KochInstitut (RKI) at national level. Adding to the complexity of
Germany's health-care infrastructure are health-care providers that are mainly operating in the private sector, with health-care services reimbursed by the German health security system.

The main components of the new law take into account fifteen notifiable diseases, more than fifty pathogens, and standardised case definitions for surveillance that must be used by the reporting health departments:

\begin{tabular}{|c|c|}
\hline \multicolumn{2}{|c|}{ NOTIFIABLE DISEASES } \\
\hline Suspected diagnosis, illness and death & Illness and death \\
\hline $\begin{array}{l}\text { - Botulism } \\
\text { - Cholera } \\
\text { - Diphtheria } \\
\text { - Human spongioform encephalopathy } \\
\text { - Acute viral hepatitis } \\
\text { - Haemolytic-uremic syndrome (HUS) } \\
\text { - Viral haemorrhagic fever } \\
\text { - Measles } \\
\text { - Meningococcal disease } \\
\text { - Anthrax } \\
\text { - Poliomyelitis } \\
\text { - Plague } \\
\text { - Rabies } \\
\text { - Typhoid / paratyphoid fever }\end{array}$ & - Tuberculosis \\
\hline
\end{tabular}




\section{NOTIFIABLE EVIDENCE OF PATHOGENS}

1. Adenovirus

2. Bacillus anthracis

3. Borrelia recurrentis

4. Brucella sp.

5. Campylobacter $s p$.

6. Chlamydia psittaci

7. Clostridium botulinum

8. Corynebacterium diphtheriae

9. Coxiella burnetii

10. Cryptosporidium parvum

11. Ebola viru

12. a) EHEC

b) E. coli, enteropathogenic

13. Francisella tularensis

14. FSME-Virus

15. Yellow fever virus

16. Giardia lamblia

17. Haemophilus influenzae

18. Hanta virus

19. Hepatitis A virus

20. Hepatitis B virus

21. Hepatitis $\mathrm{C}$ virus (non-chronic)

22. Hepatitis D virus

23. Hepatitis E virus
24. Influenza virus

25. Lassa virus

26. Legionella $s p$.

27. Leptospira interrogans

28. Listeria monocytogenes

29. Marburg virus

30. Measles virus

31. Mycobacterium leprae

32. Mycobacterium tuberculosis

33. Neisseria meningitidis

34. Norwalk-like virus

35. Polio virus

36. Rabies virus

37. Rickettsia prowazekii

38. Rotavirus

39. Salmonella paratyphi

40. Salmonella typhi

41. Salmonella, other

42. Shigella $s p$.

43. Trichinella spiralis

44. Vibrio cholerae 01 and 0139

45. Yersinia enterocolitica

46. Yersinia pestis

47. Other pathogens of haemorrhagic fever
In addition, the diagnosis of the following six pathogens is reported directly to the RKI:

\author{
- Treponema pallidum \\ - HIV \\ - Echinococcus sp. \\ - Plasmodium sp. \\ - Rubella virus (congenital infection) \\ - Toxoplasma gondii (congenital infection)
}

Case definitions, compatible with European Union case definitions, must be used by reporting health authorities based on clinical criteria, laboratory confirmation, and epidemiological data. Improvements in methods of reporting have been implemented with electronic transmission of data and collation of information in databases. German law requires case reporting for notifiable diseases and vaccination status, where applicable. The new reporting forms allow for reporting of additional data such as information on risk factors. These results are then published in Germany's weekly epidemiological bulletin, thereby providing timely feedback to the health and public health community. In addition, local and state health departments and the RKI all have electronic access to the local, State, and national data, respectively, which allow them to conduct more detailed analyses and to take any necessary actions without delay.

Section 6 of the Infektionsschutzgesetz also covers adverse events following vaccination that exceed the normal post-vaccination reactions. The criteria for defining adverse events following vaccination are determined by the vaccination recommendations of the Ständige Impfkommission (STIKO) - the German advisory committee on vaccination practices. These adverse events must be reported to the local and state health departments, and then to the Paul Ehrlich-Institut and the RKI.

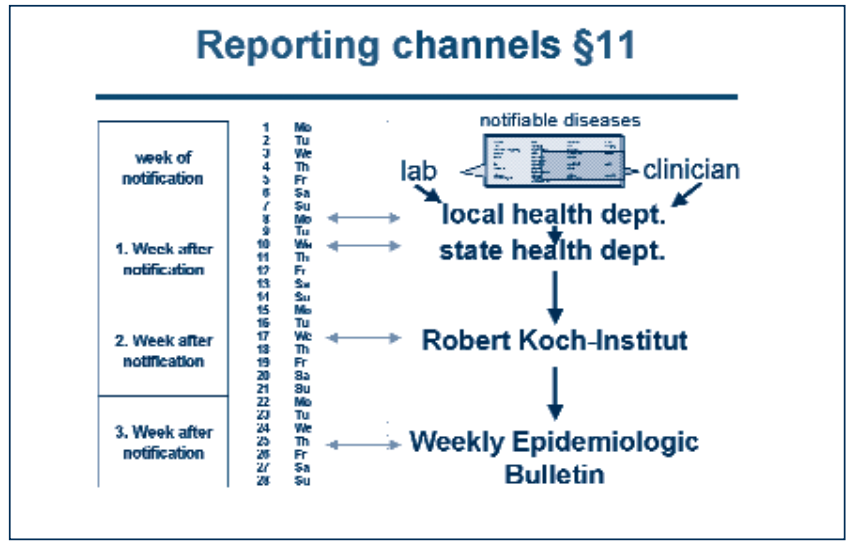

Assessment of vaccination coverage (Section 34 of the IfSG) is derived from data provided in health department records that detail the immunisation status of children at school-age entry (approximately six years old). These aggregated data are reported to the State health departments and to the RKI. The basic immunisation schedule, however, should be completed by twentyfour months of age.

\section{Conclusions}

Since the Infektionsschutzgesetz was implemented, improvements have already been made in terms of surveillance, early detection of cases, and more stringent prevention and control measures.

Based on a presentation by Dr Michael Kramer, Federal Ministry of Health and Social Security, Bonn, Germany. 


\section{Epidemiology of hepatitis A in Germany}

Hepatitis A is a notifiable disease in Germany as specified by the Infektionsschutzgesetz (IfSG), Germany's infection protection law [1]. Clinical diagnoses are reported by physicians; acute infections must be reported by laboratories. Additional information such as data on vaccination status and country where the infection probably occurred is collected. However, information on whether an individual belongs to a risk group (e.g., men who have sex with men, injecting drug users, and immigrants) is not available in the surveillance data, and contact tracing remains the responsibility of local health departments.

A case definition for hepatitis A in Germany (updated on 1 January 2004) has been established, which allows for a standardisation and differentiation of the reported cases [2]. European case definitions are taken into account. The case definitions include categories according to diagnostic certainty and distinguish among only clinical, clinical and epidemiological, clinical and laboratory, or purely laboratory confirmation for each case.

The clinical, laboratory, and epidemiological criteria are as follows:

- Clinical criteria

- Jaundice

- Fever

- Abdominal discomfort

- High transaminase levels

- Laboratory criteria

- Detection of hepatitis A virus (HAV) RNA in serum or stool (PCR)

- Detection of HAV antigen in stool (ELISA)

- Positive for HAV IgM

- Significant rise in anti-HAV IgG titre (paired sera)

- Epidemiological criteria

- Epidemiological link to a laboratory confirmed case of HAV

- Person-to-person transmission

- Consumption of same implicated food

- Consumption of food in which HAV was detected

\section{Epidemiological trends}

Hepatitis A in Germany shows a marked decline in incidence since 1980, as illustrated by the figure below. Interestingly, the incidence declined much more impressively in East Germany.

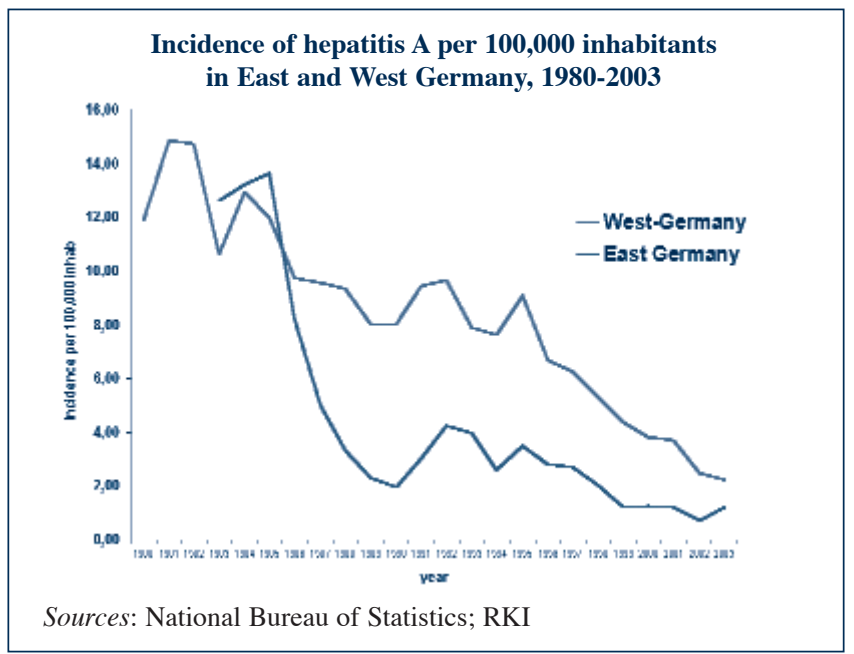

Incidence of Hepatitis A in Germany by Federal State, 2002

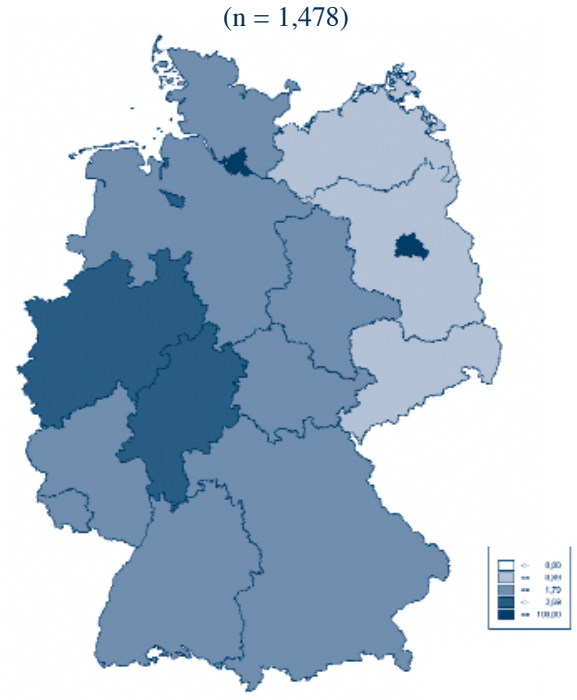

Source: Robert Koch-Institut [3]

The distribution of incidence by State in the year 2002 reflects the higher incidence in the western States and the city-States of Berlin, Bremen, and Hamburg (figure above). There is a clear seasonal pattern with more cases occurring after the end of the summer holidays.

The incidence of cases of HAV infection by gender and age group for the year 2002 is highest among the younger age group of five to nine years, with approximately 8 cases per 100,000 inhabitants among males, and approximately 7 cases per 100,000 inhabitants among females [3].

The prevalence of anti-HAV antibodies, according to the German National Health Survey of 1998 [4], was highest among those in older age groups (from sixty to seventy-nine years) with relatively low rates among younger people, a situation that highlights the risk of hepatitis A outbreaks.

For 4,279 of the 5,144 cases $(83.2 \%)$ of HAV infection reported between 2001 and 2003, there is information available on the probable country of infection; among them, 61.6\% (2,634 cases) were acquired in Germany, and $13.5 \%$ (577 cases) were acquired in Turkey.

\section{Outbreaks}

With decreasing seroprevalence the risk for outbreaks is increasing. Between 2001 and 2003, a considerable number of outbreaks of HAV infection were reported, as shown in the table below. However, only few involved more than 5 cases. In 2000 / 2001, the German and Spanish authorities jointly investigated an outbreak that occurred on the Island of Ibiza (Spain) among local residents as well as German tourists. Between January and May 2003 a major outbreak occurred in Bavaria (southern Germany) involving at least 64 cases, among whom were men having sex with men.

Outbreak-related cases of HAV infection in Germany, 2001-2003

$\begin{array}{lccc}\text { Outbreaks } & \mathbf{2 0 0 1} & \mathbf{2 0 0 2} & \mathbf{2 0 0 3} \\ \text { Number of outbreaks } & 96 & 93 & 92 \\ \text { Number of cases involved } & 229 & 272 & 288 \\ \text { Number of outbreaks }>\mathbf{5} \text { cases } & 11 & 14 & 10 \\ \text { Source: } \text { Robert Koch-Institut [5] } & & & \end{array}$




\section{Conclusions}

The incidence of notified cases of HAV infection in Germany continues to decrease. Still, as the surveillance data contain no information on risk factors for infection such as sexual preference, intravenous drug abuse, or the ethnic background of the cases, there is a clear need for more research in this field.

With decreasing seroprevalence the risk for outbreaks is increasing. Outbreak investigations are the basis for the implementation of control measures, but they can also help to identify new risk factors. Outbreak investigation requires human resources. Germany needs to continue to train more field epidemiologists as experts in outbreak management. International collaboration can be fundamental for the discovery and the study of outbreaks, and should be further enhanced.

\section{References}

[1] Infection Protection Act - Gesetz, zur Verhütung und Bekämpfung von Infektionskrankheiten beim Menschen (Infektionsschutzgesetz IfSG). Bundesgesetzblatt 2000; 1045.
[2] Robert Koch-Institut. Falldefinitionen. Bundesgesundheitsblatt - Gesundheitsforschung - Gesundheitsschutz 2004; 47.

[3] Robert Koch-Institut. Infektionsepidemiologisches Jahrbuch meldepflichtiger Krankheiten für 2002. Mercedes-Druck, Berlin 2003; also available at

http://www.rki.de/INFEKT/IFSG/JAHRBUCH-2002.PDF

[4] Thierfelder W, Hellenbrand W, Meisel H, Schreier E, Dortschy R. Prevalence of markers for hepatitis A, B and C in the German population. Results of the German National Health Interview and Examination Survey 1998. Eur J Epidemiol 2001; 17:429-435.

[5] Robert Koch-Institut. Infektionsepidemiologisches Jahrbuch meldepflichtiger Krankheiten für 2003. Mercedes-Druck, Berlin 2004; also available at

http://www.rki.de/INFEKT/IFSG/JAHRBUCH-2003.PDF

Based on a presentation by Dr Katharina Alpers, Robert KochInstitut, Berlin, Germany.

\section{Epidemiology of hepatitis B in Germany}

Hepatitis B has been a notifiable disease in Germany for well over twenty years - since 1980 in West Germany, and since 1983 in the East. A case definition for hepatitis B was established in 2001 by the Infektionsschutzgesetz. (IfSG) or infectious disease protection law, based upon a clinical picture together with laboratory findings for acute cases Also reportable are positive laboratory findings where the symptoms are either absent or unknown.

The notification process begins with clinicians and laboratories reporting cases to local health departments, which collate the information. These data are then passed on to the State (Land), and finally transmitted at national level to the Robert Koch-Institut.

The new disease surveillance system for hepatitis B and hepatitis C, which was introduced in 2001 as part of the Infektions schutzgesetz, also includes reports of vaccination status, hospitalisation data and risk factors. In addition, a project called 'Enhanced Surveillance of Risk Factors for Hepatitis B and C' is carried out in collaboration with HepNet, a German network of competence (www.kompetenznetz-hepatitis.de), which aims at further elucidation of current risk factors.

\section{Prevalence}

A number of serosurveys that were carried out between 1990 and 1998 among the general population in Germany provide valuable data on hepatitis B seroprevalence. Data for 1998 show that the overall prevalence of anti-HBc increases with age and that prevalence is higher in Western States than in the East. The highest prevalence rates are among individuals in the seventy to seventynine year age group, with $17.6 \%$ prevalence in the West compared with $13 \%$ prevalence in the East.

\section{Incidence}

Hepatitis B incidence rates in Germany have been declining since 1993, particularly in 2002 to 2003. Notification data for 2002 by gender and age group show that the highest incidence of hepatitis $\mathrm{B}$ is among females between twenty and twenty-four years, and among males between twenty-five and twenty-nine years, with decreasing incidence among older age groups for both sexes.

Hospitalisation data for the period 1998 to 2001 show that the number of deaths due to hepatitis increased among patients with chronic infection from approximately 600 in 1998 to approximately 800 in 2001, and decreased slightly for acute cases of hepatitis B and unspecified hepatitis.
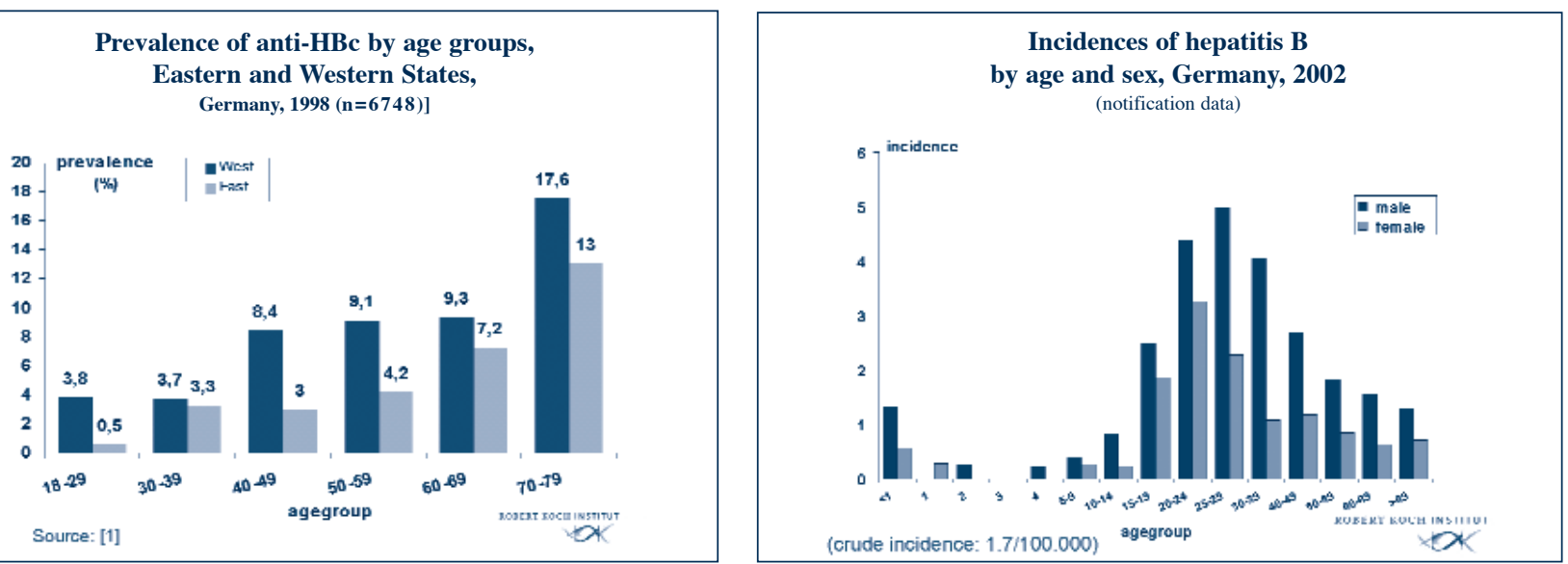


\section{Notified hepatitis B cases per 100,000 inhabitants, Germany, 1997-2003}
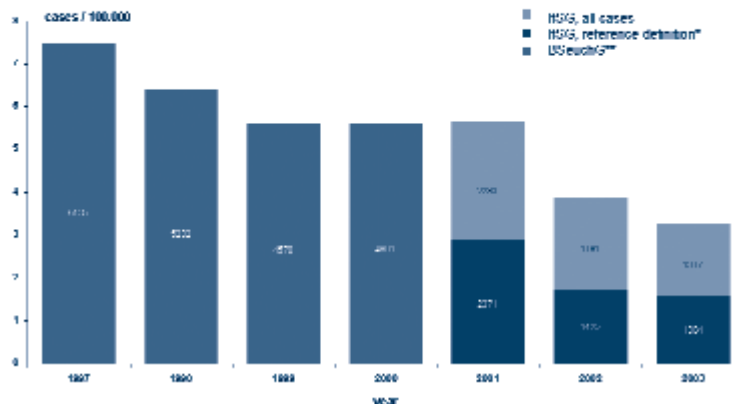

*IfSG, reference definition: a case has to be laboratory confirmed and has to meet criteria of the 'clinical picture'

**BSeuchG: Bundesseuchengesetz (the former infectious disease law)

\section{Risk groups}

2002 notification data, based on 578 cases, show that the highest number of reported exposures for HBV is among those engaging in heterosexual intercourse (resulting in more than half of the total number of cases), followed by injecting drug users, those engaging in homosexual intercourse, and those living in households with a chronically infected person.

\section{Blood donors}

In 1970, Germany implemented a screening programme for blood products. The calculated residual risk for transfusion-transmitted HBV infection in 1999 was estimated at 1:232,000 [2]. Since 1995, there have been eleven reports of transfusion-transmitted HBV infection. In 2001, the prevalence among blood donors [3] was $0.16 \%$, and the incidence 1.43 per 100,000 donations. Within the general population $[1,4]$, the prevalence of $\mathrm{HBsAg}$ was $0.6 \%$ and the incidence in 20012.96 per 100,000 inhabitants.

\section{Antenatal screening}

Pregnant women in Germany are routinely screened for HBsAg after a 32-week gestation. If the test is positive, the newborn will receive $\mathrm{HBIg}$ and active immunisation at birth.

\section{Hepatitis B vaccination in Germany}

The Ständige Impfkommission (STIKO), the German Standing Committee on Immunisation, comprising a group of experts affiliated with the Robert Koch-Institut, provides guidelines and issues recommendations to health authorities of the Federal States who then decide on which vaccines should be publicly recommended.
Up until 1995, hepatitis B vaccination was recommended only for risk groups: among others, health-care workers, recipients of blood products, dialysis patients, those with chronic liver diseases, men who have sex with men, HIV positives without prior contact with HBV, sex workers, injecting drug users, prisoners, patients in psychiatric institutions, close contacts of carriers, those professionally exposed besides the health professions, newborns of carrier mothers, and travellers to endemic countries.

Since 1995, hepatitis B vaccine has been recommended for routine administration to infants, children, and adolescents. Hepatitis B vaccination coverage is measured at school-entry age of six years through data obtained from children's vaccination certificates. In 2002, coverage for hepatitis B vaccination at school-entry in Germany reached $67 \%$.

Since 2000, two hexavalent combination vaccines containing the hepatitis B component have been approved by the European regulatory authorities, and are now widely used in Germany, having been well accepted by paediatricians and parents of young children.

\section{Sporadic hepatitis B outbreaks}

Hepatitis B outbreaks are rare now in Germany. Sporadically occurring clusters of cases in the past seemed to be attributed to breaches in hygiene in long-term care facilities and dialysis centres.

\section{References}

[1] Thierfelder W, Hellenbrand W, Meisel H, Schreier E, Dortschy R. Prevalence of markers for hepatitis A, B and C in the German population. Results of the German National Health Interview and Examination Survey 1998. Eur J Epidemiol 2001; 17:429-435.

[2] Glück D, Kubanek B, Maurer C, Petersen N. Seroconversion of $\mathrm{HIV}, \mathrm{HCV}$, and HBV in blood donors in 1996 - Risk of virus transmission by blood products in Germany. Infusionsther Transfusionsmed 1998; 25:82-84.

[3] Offergeld R, Stark K, Hamouda O. Infections in blood donors [in German]. Bundesgesundheitsbl Gesundheitsforsch Gesundheitsschutz, 2003; 46:775-779.

[4] German notification data; Yearbook 2001. Ed. Robert KochInstitut, ISBN 3-89606-040-6; also available at http://www.rki.de/INFEKT/IFSG/JAHRBUCH-2001.PDF

Based on a presentation by Dr Doris Radun, Robert Koch-Institut, Berlin, Germany.

\section{Development of hepatitis B prevention in Germany - the first 10 years}

The first hepatitis B vaccine, a plasma-derived vaccine, was authorised in Germany in 1982. At that time, the vaccine was only recommended for individuals at high risk for $\mathrm{HBV}$ infection as defined by the Ständige Impfkommission (STIKO), the German Standing Committee on Immunisation. These high-risk groups comprised:

- Health-care workers

- Contacts of carriers

- Recipients of blood products

- Patients of institutions for the mentally disabled
- Haemodialysis patients

- Men who have sex with men

- Sex workers

- Parenteral drug users

- Prison inmates

- Travellers to highly endemic countries

- Newborns of carrier mothers

The costs for hepatitis B vaccination were reimbursed either by the employer (e.g., in the case of health-care workers), or by the 
insurance company (e.g., patients, newborns, among others).

Initially, due to lack of adequate information about the newly licensed vaccine, there was some hesitancy in its acceptance within the medical profession. Safety concerns regarding the use of plasma-derived material, which was thought to play a role in HIV transmission, also played a role in the vaccine's slow uptake.

Between 1985 and 1992 less than 50\% of medical doctors, and $35 \%$ to $59 \%$ of nurses in Germany were immunised against hepatitis B. Less than $10 \%$ of injecting drug users and homosexual men were immunised. The vaccination coverage, however, was higher (between 60\% and 90\%) among haemodialysis patients during that period.

Questions were also raised about minimal antibody concentrations needed for protection and the vaccine's long-term protection. These issues eventually led to a decision to convene a meeting in Ising, Bavaria, in February 1988 to discuss the vaccine's long-term protection potential [1]. Some of the key discussion points were that:

- An individual with a peak lower than $10 \mathrm{IU} / 1$ (non-responder) 4-8 weeks after the basic course of vaccination probably lacks protection against $\mathrm{HBV}$ infection. Individuals with peak antiHBs levels of 10-100 IU/l (low responder) generally lack antiHBs a few years later. A good response is regarded as anti-HBs levels of $\geq 100 \mathrm{IU} / 1$.

- Some of the non-responders will acquire adequate anti-HBs levels after additional vaccine booster doses. For low responders, an additional booster within one year should be considered. However, no unanimity was reached on this point.

- Until more data are available, one might consider revaccinating individuals when anti-HBs levels fall below $10 \mathrm{IU} / \mathrm{l}$ or once after five to seven years after the initial course of vaccination.

By the early 1990s, many at-risk individuals were still not being vaccinated against hepatitis B in Germany. More new cases of hepatitis B (and syphilis) were also being reported, with more than two thirds of all cases occurring within the general population among individuals not considered at risk. In view of the increase in the number of HBV infections, Germany's vaccination strategy against hepatitis B was beginning to be re-examined.

In 1993, the results of the ANOMO study [2] based on sentinel surveillance of HIV and other sexually transmitted infections, including hepatitis $\mathrm{B}$, indicated that there had been massive underreporting (80\% to $90 \%)$ of all infections. Instead of the 5,500 reported symptomatic infections, there were in fact approximately 50,000 new infections.

\section{Hepatitis B: epidemiological situation in Germany 1993 reported vs. calculated incidence

\begin{tabular}{|c|c|c|}
\hline & $\begin{array}{l}\text { symptomatic } \\
\text { infections }\end{array}$ & $\begin{array}{l}\text { all } \\
\text { infections }\end{array}$ \\
\hline reported & 5497 & \\
\hline $\begin{array}{l}\text { calculated under the assumption } \\
\text { of underreporting of } 60-80 \%\end{array}$ & $\begin{array}{r}13743 \\
-27485\end{array}$ & $\begin{array}{r}27485 \\
-54970\end{array}$ \\
\hline ANOMO-study [2] & 25689 & 51378 \\
\hline $\begin{array}{l}\text { expected value due to anti-HBc- } \\
\text { prevalence data }(1990 / 91) \text { [3] }\end{array}$ & & 52589 \\
\hline
\end{tabular}

The epidemiological situation in Germany in 1993 was as follows

- ca 500,000 HBsAg carriers

- ca 50,000 new HBV infections per year

- most infections were transmitted sexually

These epidemiological data, in view of the poor hepatitis B vaccination coverage, led to changes in STIKO recommendations. In 1995, hepatitis B vaccination was recommended for routine administration to infants, children, and adolescents, together with the previous recommendations for risk groups.

\section{References}

[1] Anonymous. Immunisation against hepatitis B. Lancet 1988; i:875-876.

[2] Kirschner W, Schwartländer B. Sentinel Surveillance of HIV and Other Sexually Transmitted Diseases: Results from the ANOMO Study, 1988 to 1994. Ministry of Health Publication Series. Baden-Baden. Nomos, 1996, No. 63. [Article in German] [3] Thefeld W. Hepatitis B Durchseuchung in der deutschen Bevölkerung. Bundesgesundhbl 1994; 37:372-377.

Based on a presentation by Dr Wolfgang Jilg, Institute for Medical Microbiology and Hygiene, University of Regensburg, Regensburg, Germany.

\section{Screening pregnant women for hepatitis B: results from two studies}

\section{Mother-to-infant transmission of $\mathbf{H B V}$}

Newborns infected with HBV have a $25 \%$ lifetime risk of primary hepatocellular carcinoma or cirrhosis [1]. The estimated risk of HBV infection for newborns in Germany is shown in the table on the right.

\section{Effectiveness of risk-group screening}

The first German regulations for HBsAg screening of pregnant women went into effect in 1984 when testing had to be performed on all pregnant women considered at risk for HBV infection. This testing had to be carried out after the $32^{\text {nd }}$ week of pregnancy as close as possible to the time of delivery. The risk groups were defined as follows:

\section{Perinatal transmission of hepatitis $B$}

estimated risk of infection for newboms in Germany

\begin{tabular}{|c|c|c|c|}
\hline \multicolumn{2}{|c|}{$\begin{array}{l}\text { HBsAg-pos. } \\
\text { pregnant women }\end{array}$} & \multirow[t]{2}{*}{$\begin{array}{l}\text { risk of } \\
\text { transmission }\end{array}$} & \multirow[t]{2}{*}{$\begin{array}{l}\text { newborns } \\
\text { at risk }\end{array}$} \\
\hline total & 7000 & & \\
\hline \multirow[t]{2}{*}{$\begin{array}{l}\mathrm{HBeAg+} \\
\text { anti-HBe+ }\end{array}$} & $\begin{array}{l}1050 \\
5950\end{array}$ & $\begin{array}{r}85 \% \\
6 \%\end{array}$ & $\begin{array}{l}893 \\
357\end{array}$ \\
\hline & & total & 1250 \\
\hline
\end{tabular}


- Health-care workers

- People from endemic countries

- Contacts of carriers

- Recipients of blood products

- Patients of institutions for the mentally disabled

- Haemodialysis patients

- Heterosexuals with multiple sex partners

- Parenteral drug users

- Prison inmates

Since high-risk screening criteria can miss a substantial proportion of HBsAg-positive women, Germany revised its screening regulations in 1994 to extend $\mathrm{HBsAg}$ testing to all pregnant women within the same time frame as required in the 1984 regulation.

In a study [4] carried out among 912 pregnant women who were tested for HBsAg, thirteen of the women tested positive. Nine of them were from endemic countries, and four of them were not considered at risk for HBV infection. These data suggest that $30 \%$ of these women would not have been tested if only high-risk screening criteria had been applied.

The effectiveness of universal maternal screening in Germany was demonstrated in two surveys that were carried out:

- A retrospective analysis in Berlin with ca 4,000 participants [5]

- A prospective study in Bavaria with ca 6,000 participants [6]

Conclusions of the Berlin retrospective study

In this retrospective survey, all of the 3,963 women who participated delivered between 1996 and 1998 in the Department of Gynaecology and Obstetrics of the Free University of Berlin. The medical charts of the mother and her infant were reviewed for documentation of maternal HBsAg screening.

The results of this survey showed that HBsAg tests had not been performed or were not available in $19.5 \%$ of women who delivered after week 32 . In marked contrast with these results, only $5.2 \%$ in tests carried out for rubella antibody were missing.

\begin{tabular}{|lrrr|}
\hline \multicolumn{3}{l}{$\begin{array}{l}\text { Effectiveness of universal maternal screening } \\
\text { in Germany - retrospective analysis [5] }\end{array}$} \\
\hline participants & $\mathbf{n}$ & $\begin{array}{r}\text { HBsAg test } \\
\text { documented } \\
\mathbf{n}(\%)\end{array}$ & $\begin{array}{c}\text { not tested/result } \\
\text { not available } \\
\%\end{array}$ \\
\hline German & 2988 & $2153(72.1)$ & 27.9 \\
non-German & 975 & $663(68.0)$ & 32.0 \\
all & 3963 & $2816(71.1)$ & 28.9 \\
after week 32 & 3589 & $2888(80.5)$ & 19.5 \\
\hline
\end{tabular}

The retrospective study also demonstrated that the HBsAg carrier rate in the tested women was similar to those not tested before delivery: $1.17 \%$ vs. $1.05 \%$

\begin{tabular}{|c|c|c|c|}
\hline \multicolumn{4}{|c|}{$\begin{array}{l}\text { Effectiveness of universal maternal screening } \\
\text { in Germany - retrospective analysis [5] }\end{array}$} \\
\hline $\begin{array}{l}\text { HBsAg test } \\
\text { result at delivery }\end{array}$ & $n$ & $\begin{array}{l}\text { HBsAg test } \\
\text { positive } \\
\text { n (\%) }\end{array}$ & \\
\hline available & 2815 & $33(1.17)$ & $\begin{array}{l}8 \text { German } \\
22 \text { non-German }\end{array}$ \\
\hline $\begin{array}{l}\text { not available, } \\
\text { tested after delivery }\end{array}$ & 1148 & $12(1.05)$ & $\begin{array}{l}3 \text { German } \\
9 \text { non-German }\end{array}$ \\
\hline
\end{tabular}

Conclusions of the Bavarian prospective study

In this prospective study [6], 6,083 women participated, all of whom delivered between July 1997 and December 1998 in the obstetric wards of eleven clinics in Bavaria. The pregnancy documents of the women entering the obstetrics wards were examined to determine if HBsAg screening had been performed and if so, when the screening was performed and the results of the test.

For HBsAg, the test results were available for 4,744 tested women, of whom $42(0.89 \%)$ tested HBsAg positive. Twelve of the women were German, thirteen were non-German, and thirteen were not identified by nationality. Among the twelve German women, two were drug users, and one was a medical professional.

At the Ludwig-Maximilians-Universität (LMU) of Munich, all women who were not tested before delivery were tested after they delivered. Among the 577 women who were tested before delivery, twelve $(2.1 \%)$ were $\mathrm{HBsAg}$ positive. Among the 301 women who were tested after their delivery, four (1.3\%) tested HBsAg positive.

\section{Conclusions}

The conclusions that may be drawn from these data are that approximately $20 \%$ of pregnant women are not tested for HBsAg before delivery, and that about $1 \%$ of women are HBsAg positive. According to these figures, approximately 1,400 HBsAg-positive pregnant women are not identified, and subsequently give birth to about $250 \mathrm{HBV}$-infected newborns, 225 of whom become chronic carriers.

This situation raises questions as to whether HBsAg screening earlier in pregnancy, as is done for rubella, would be more effective in identifying women at risk of HBV infection. It also suggests that it may be necessary to go beyond current screening practices, and to consider administering a birth dose of hepatitis $\mathrm{B}$ vaccine. This last option, however, has been rejected by the Ständige Impfkommission (STIKO). In the meantime, the European Union's approval of two new hexavalent vaccines containing hepatitis B antigen is more likely to be accepted by mothers who might otherwise refuse the hepatitis $B$ vaccine when administered separately.

\section{References}

[1] Beasley RP, Hwang LY. Epidemiology of Hepatocellular Carcinoma. In: Vyas, Dienstag, Hoofnagle (Eds). Viral hepatitis and liver disease. New York, 1984, 209-224.

[2] Stück B, Jilg W. Universal hepatitis B vaccination in childhood. Die Gelben Hefte 1996; 36:106-113. [Article in German]

[3] Knöll A, Rohrhofer A, Kochanowski B, Wurm EM, Jilg W. Prevalence of precore mutants in anti-HBe-positive hepatitis B virus carriers in Germany. J Med Virol 1999; 59:14-18.

[4] Niesert S, Messner U, Tillmann HL, Gunter HH, Schneider J, Manns MP. Prevalence of hepatitis B in pregnancy and selective screening. Geburtshilfe Frauenheilkd 1996; 56:283-286. [Article in German]

[5] Parasher KS, Bartsch M, Gstettenbauer M, Entezami M, Versmold H, Stück B. Universal hepatitis B screening in pregnancy - a still not solved problem in obstetrics. Dtsch Ärztebl 2001; 98:A329-A331. [Article in German]

[6] Dausch E, Jilg W. HBsAg-screening in pregnancy performance and efficiency. Geburtshilfe Frauenheilkd 2001; 61:682-685. [Article in German]

Based on a presentation by Dr Wolfgang Jilg, Institute for Medical Microbiology and Hygiene, University of Regensburg, Regensburg, Germany. 


\section{Groups at risk for hepatitis B infection - who should be vaccinated}

In Germany, four main groups at risk of hepatitis B virus infection have been identified as candidates for hepatitis B vaccination. It is estimated that within the German population, these four groups could amount to over three million people.

\begin{tabular}{|lc|}
\hline Risk group & Population in millions \\
\hline Medical staff & 1.85 \\
Men who have sex with men & 1.23 \\
Injecting drug users & 0.12 \\
Haemodialysis patients & 0.12 \\
\hline All groups & 3.32 \\
\hline
\end{tabular}

In addition to the above-mentioned groups, other groups considered at risk for HBV infection are heterosexuals with multiple sex partners (e.g., sex workers), travellers to areas of high hepatitis B endemicity, immigrants and refugees from areas of high hepatitis B endemicity, household contacts and sex partners of HBV carriers, prison inmates and staff, and clients and staff in institutions of the mentally disabled.

\section{Travellers to and from areas of high hepatitis B endemicity} The main groups at risk in travel to and from areas of high hepatitis B endemicity and for whom hepatitis B vaccination is recommended are:

- individuals who spend prolonged periods of time in highendemic areas, such as expatriates working in developing countries

- occupational groups such as the military and aid workers

- travellers whose activities or lifestyle place them at risk (e.g., heterosexuals or homosexuals engaging in casual sex, injecting drug users)

- travellers who are likely to engage in acupuncture, tattooing, or body piercing

- travellers who may need to undergo medical or dental procedures while abroad.

The risk of HBV infection is $10 \%$ to $15 \%$ in travellers to and from endemic areas with either voluntary or involuntary exposure to blood and body fluids. The monthly incidence for HBV infection is $80-420$ per 100,000 travellers; the monthly incidence for symptomatic HBV infection is 25 per 100,000 travellers.

An accelerated hepatitis B vaccination schedule is recommended for travellers to high-endemic areas and for drug users:

\section{Schedule I}

Standard dose at $0,1,2$, and 12 months

Seroprotection rates:

- 3 months after first dose: $84 \%-100 \%$

- 13 months after first dose: $97 \%-100 \%$

\section{Schedule II}

Standard dose at 0,1 , and 3 weeks, and 12 months

Seroprotection rates in both groups:

- 7 - 8 months after first dose: $93 \%-95 \%$
The risk for acquiring sexually transmitted infections (STI) among expatriates working in developing countries has also been established taking into account the duration of the relationship and type of protection used during sexual activity.

\section{HBV seropositivity among injecting drug users}

Among injecting drug users, increased HBV seropositivity was noted with long-term drug users, and higher frequency of syringe sharing and imprisonment.

In a prison syringe-exchange programme [1] in which 166 inmates stopped sharing syringes, there were no seroconversions for HBV or for HIV, despite prevalence rates of $53 \%$ and $18 \%$, respectively.

\section{Immunostimulatory adjuvants of hepatitis B vaccines}

Monophosphoryl Lipid A (MPL) and saponin from Quillaja saponaria (QS21) belong to the group of immunostimulatory adjuvants having pathogen-associated molecular patterns (PAMP). These adjuvants activate cells of the immune system and induce Th1 (IL-2, IFN- $\alpha$ ) and antibodies of the IgG2a isotype.

\begin{tabular}{|c|c|c|}
\hline \multicolumn{3}{|c|}{$\begin{array}{c}\text { Hepatitis B vaccination of non-responders* } \\
\text { with the standard vaccine }(\mathrm{n}=37) \text { and HBsAg/AS04 (3-deacylated } \\
\text { monophosophoryl lipid A / MPL) }(\mathrm{n}=40) \\
\text { - Seroprotection rates and geometric mean titres (GMT) - }\end{array}$} \\
\hline & HBsAg & HBsAg / MPL \\
\hline $\begin{array}{l}\text { Seroconversion rate } \\
\text { GMT }\end{array}$ & $\begin{array}{c}67.6 \% \\
111 \mathrm{IU} / 1\end{array}$ & $\begin{array}{c}97.5 \% \\
1,937 \mathrm{IU} / 1\end{array}$ \\
\hline \multicolumn{3}{|c|}{$*<10 \mathrm{IU} / \mathrm{l}$ anti-HBs after 4 doses of standard vaccine } \\
\hline \multicolumn{3}{|c|}{ Source: Ambrosch et al., 2000 [2] } \\
\hline
\end{tabular}

Among recipients of organ transplants, lower seroconversion rates, lower peak antibody levels, and faster decline of antibody titres may be seen. There is also increased risk of infection following transplantation that may lead to increased susceptibility, severe disease, high rate of complications, and graft rejection.

It is expected that new adjuvants will contribute to developing new vaccines that will require fewer doses and achieve higher efficacy, particularly among non-responders and recipients of organ transplants.

\section{References}

[1] Stark K, Bienzle U, Vonk R, Guggenmoos-Holzmann I. History of syringe sharing in prison and risk of hepatitis B virus, hepatitis $\mathrm{C}$ virus (HCV), and human immunodeficiency virus infection among injecting drug users in Berlin. Int J Epidemiol 1997; 26:1359-1366.

[2] Ambrosch F, Wiedermann G, Kundi M, Leroux-Roels G, Desombere I, Garcon N et al. A hepatitis B vaccine formulated with a novel adjuvant system. Vaccine 2000; 18:2095-2101.

Based on a presentation by Dr Ulrich Bienzle and Dr Matthias Günther, Institut für Tropenmedizin, Berlin, Germany. 


\section{Universal vaccination against hepatitis B in Germany - a paediatrician's point of view}

In the area of Bielefeld, Germany, parents appear to be generally well informed about hepatitis B vaccination, having received information about it during the mother's pregnancy and having been made aware of the risks of HBV infection. The most important arguments presented to pregnant women to have their infants vaccinated are:

- To prevent perinatal HBV transmission

- To prevent complications of HBV infection in newborns and young children

- To comply with Germany's recommended vaccination schedule for hepatitis B

- Ease of administration of hepatitis B vaccine through use of the hexavalent combined vaccine

- Lack of accessibility to young adults to administer the vaccine.

The main risk period of contracting HBV infection is during adolescence and young adulthood. Postponing hepatitis B vaccination until the age of fourteen years is not advisable as HBV infections, although rare among young children, still occur in Germany every year.

There appear to be some challenges in convincing adolescents to become vaccinated. The prevention system in Germany ends at the age of six years. Children who are older than nine or ten years were born before Germany's introduction of hepatitis B vaccination into the official vaccination calendar. When the hepatitis $\mathrm{B}$ vaccine officially became part of the vaccination schedule, the period of preventive examination was finished and, consequently, parents were not informed of the importance of the vaccine. One solution to this problem would be to provide information about hepatitis B through the school system. However, the health-care system in Germany does not have enough staffing resources to do this and paediatricians are not allowed to provide this information directly via the school system.
Other factors influencing adolescents' reluctance to receive the vaccine appear to be (1) a general fear that they would 'out' themselves when visiting a doctor's practice and so avoid contact with the medical community, and (2) fear of the injection. The problem is compounded by the fact that teachers also lack sufficient information regarding vaccination. In general, it would appear that adolescents as well as teachers do not have a clear understanding of the necessity of prevention.

A relatively new check-up system has been set up in Germany, allowing adolescents to participate in a preventive examination at the age of thirteen years. However, only $25 \%$ to $40 \%$ of adolescents participate in the programme. Gynaecologists are also allowed to provide vaccination information to patients. In contrast, in Bielefeld $90 \%$ of the adolescents took part in the preventive examination and / or received information from a gynaecologist, suggesting that providing information on vaccination enhances uptake levels, and that outreach efforts are successful in helping to overcome otherwise low coverage.

To help meet these challenges, changes would need to be made within the health-care system in Germany with the goal of achieving staff resources comparable to what exists in public health departments, and integrating education, life style, and vaccination in order to achieve high coverage levels.

Further efforts could also be made in providing medical treatment directly in schools, with school doctors administering vaccines, providing medical information to both students and teachers, and checking and documenting the vaccination status of students.

Based on a presentation by Dr Uwe Büsching, Bielefeld, Germany.

\section{Unusual courses of hepatitis B virus infection caused by wild-type virus and escape mutants}

Hepatitis B virus was first shown in the electron microscope by David Dane in 1970 as the potential agent of hepatitis B. A sensitive PCR technique for the DNA encapsidated within this virus would be sufficient to detect $\mathrm{HBV}$ infections during incubation period, acute phase, and recovery. In many cases HBV DNA persists at low levels even after complete recovery in spite of the presence of anti-HBs and cellular immunity [1].

Usually, the screening for HBV is not achieved by detection of HBV DNA but by sensitive detection of its surface antigen, HBsAg. While such a methodology is not applicable for most viruses, $\mathrm{HBV}$ is an exception in that it induces strong overproduction and secretion of HBsAg protein as subviral particles to the blood. Chronic HBV carriers with the viral immunomodulator $\mathrm{HBeAg}$ have typically $10^{9}-10^{10} \mathrm{HBV}$ particles and $10^{13}-10^{14} \mathrm{HBsAg}$ particles per ml serum. Nevertheless, HBV DNA may be the more sensitive marker than HBsAg because even the best enzyme immune assay needs ca. $10^{6} \mathrm{HBV}$ particles to generate a positive result whereas PCR may detect $<100 \mathrm{HBV}$ particles/ml. Thus, in analytical terms one would expect PCR to be a hundred times more sensitive than HBsAg assays. However, this would be an oversimplification, because the ratio between $\mathrm{HBV}$ and $\mathrm{HBsAg}$ particle is highly variable. In early phases of infection, the excess of HBsAg may be smaller; in late phases it may be larger, because $\mathrm{HBV}$ has a more rapid turnover than HBsAg [2].

The sensitivity gap of HBsAg assays during the incubation period of an HBV infection has often been observed in transfusion medicine. From Europe [3-5], only sporadic cases are reported, but in Japan the failure to detect HBV in the early phase by even the most sensitive HBsAg assay has been reported in 76 of 11 million donations [6]. It is clear that only the minority of such HBV transmissions can be prevented by minipool testing for HBV DNA because the typical sensitivity of this screening is ca. 1000 genome equivalents $(\mathrm{ge}) / \mathrm{ml}$ and, thus, insufficient [6]. Furthermore, the duration of viraemia without HBsAg may exceed 60 days [4]. In other cases, HBsAg may never appear in spite of low-level viraemia (Dornheim and Gerlich, unpublished). 
A possibly more efficient measure would be vaccination of donors. Particularly with frequent donors this could be cost effective. However, vaccination cannot provide universal protection against HBV transmission. Low-level carriers without detectable HBsAg will most likely not be cured by an active vaccination. There are obviously several reasons why HBsAg may be undetectable in persistent HBV infection. Again, as in the early phase, the amount of HBsAg may be too low or it is masked by anti-HBs. Mini-pool testing for HBV DNA is not useful to detect such donors unless it is extremely sensitive $(<30 \mathrm{ge} / \mathrm{ml})$ [7]. In many countries anti-HBc screening of blood donors is done, but the tests for anti-HBc are still unsatisfactory [7]. There is a high proportion of unclear results in high-risk populations [8]. Furthermore, anti$\mathrm{HBc}$ may be absent in cases that later reactivated HBV. W. Gerlich is aware of two cases with anti-HBs but without anti$\mathrm{HBc}$ although no vaccination had been given. Under immunosuppressive therapy, HBV DNA appeared and reached high levels but anti-HBc remained negative. In one case antiHBs remained positive and HBsAg was severely mutated, thus reacting negative in certain $\mathrm{HBsAg}$ assays (R. Kaiser et al., in preparation). In the other case, anti-HBs disappeared and wildtype HBsAg came up. Investigations showed that this patient had originally been anti-HBs- and anti-HBc-positive (B. Gärtner, personal communica-tion). It is surprising that anti$\mathrm{HBc}$ disappeared earlier than anti-HBs in these cases. However, the usually observed stronger immu-nogenicity of $\mathrm{HBcAg}$ compared to HBsAg may not exist in unapparent HBV infections with an early immune control of virus replication (W. Gerlich, unpublished)

Vaccination is known to protect against hepatitis B disease and against persistent infection if detectable anti-HBs is induced. Unapparent HBV infection after vaccination has been observed, but usually this was long after vaccination and at low anti-HBs titres [9]. The question is whether such an infection would cause viraemia and transmission by donated blood. V. Lenz (Heidelberg) and W. Gerlich observed a vaccinated thrombocyte donor who had $>1000 \mathrm{IU} / \mathrm{l}$ anti-HBs. After three years the donor seroconverted slowly to anti-HBc. A retrospective examination using a second, more sensitive anti$\mathrm{HBc}$ assay showed that seroconversion had already occurred two years earlier. The donor had very low levels of HBV DNA in some of the donations $(<30 \mathrm{ge} / \mathrm{ml})$. In this case the infecting virus had genotype D and HBsAg subtype ayw3. Furthermore, HBsAg was mutated at P120 to S, which is known as a vaccineescape site. Despite the ca. $50 \mathrm{ml}$ plasma per thrombocyte donation, none of the 22 followed-up recipients became infected. Thus, vaccination of this blood donor provided protection both to himself and to the recipients in spite of a persisting low-level HBV infection.

Nevertheless, today's hepatitis B vaccines may not exploit the full protective potential of HBsAg as a vaccine. They were designed at a time when only the small HBs protein (SHBs) was known. Since 1984 it has been known that there are two further HBs proteins: middle and large HBs (MHBs and LHBs, respectively) [10]. Neurath had already shown in 1986 that the preS1 domain of LHBs mediates binding of HBV to liver cells [11]. Recently, Glebe et al. proved that this binding is essential in the infection process [12]. SHBs does not seem to be necessary for binding, but certain conformational antibodies against SHBs neutralise also infectivity of HBV, including vaccine-induced anti-HBs (Glebe et al. in preparation). However, the neutralising power of preS1-specific antibodies was higher.
Structural Components of HBV and HBsAg Particles

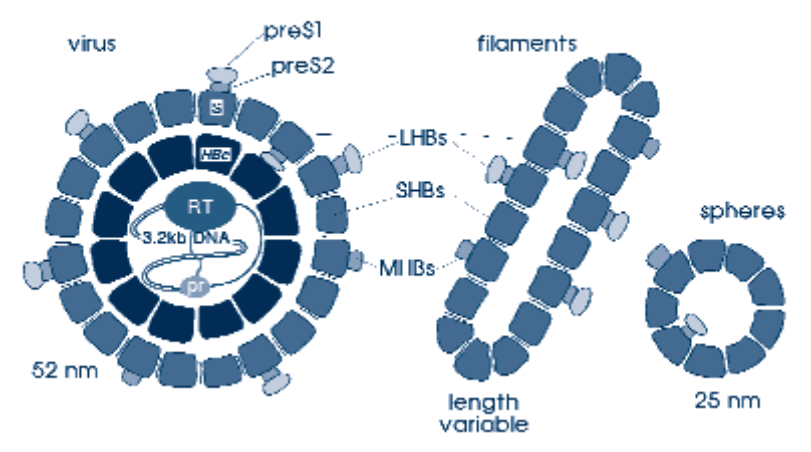

A second weak point of most vaccines is the HBsAg subtype or genotype. The predominant vaccines have genotype A2 and the subtype adw2, which occur in Europe and the USA, while $99 \%$ of the HBV carriers in the world have different genotypes or subtypes. From the literature and W. Gerlich's own experience, virtually all known vaccine failures in the presence of anti-HBs occurred with genotypes other than A. There are 11 positions in the SHBs antigen loop between positions 99 - 170 that are different between the various genotypes, three of which $(122,127$, and 160) lead to different immunodeterminants, i.e., subtypes. While crossprotection between different HBsAg subtypes has been shown in early studies with chimpanzees, it is plausible to assume a contribution of the subtype-specific determinant to protection. In escape mutants, the occurrence of other subtype determinants than expected has been observed [13]. These considerations for potential improvements in hepatitis B vaccines should not be taken as reasons not to vaccinate with the current vaccines since their efficacy is very high (> 90\%) and no serious side effects have been convincingly ascribed to them.

\section{References}

[1] Rehermann B, Ferrari C, Pasquinelli C, Chisari FV. The hepatitis B virus persists for decades after patients' recovery from acute viral hepatitis despite active maintenance of a cytotoxic Tlymphocyte response. Nat Med 1996; 2:1104-1108.

[2] Chulanov VP, Shipulin GA, Schäfer S, Gerlich WH. Kinetics of HBV DNA and HBsAg in acute hepatitis B patients with and without coinfection by other hepatitis viruses. J Med Virol 2003; 69:313-323.

[3] Roth WK, Weber M, Peterson D, Drosten C, Buhr S, Sireis W et al. NAT for HBV and anti-HBc testing increase blood safety. Transfusion 2002; 42:869-875.

[4] Meisel H, Endres A, Walther HU, Wend UC, Gerlich WH. Transmission of hepatitis B virus two months prior to HBsAg positivity of donor blood. Transfusion Medicine and Hemotherapy 2003; 30:228-231.

[5] Soldan K, Barbara JA, Dow BC. Transfusion-transmitted hepatitis B virus infection in the UK: a small and moving target. Vox Sang 2002; 83:305-308.

[6] Minegishi K, Yoshikawa A, Kishimoto S, Yugi H, Yokoya N, Sakurada M et al. Japanese Red Cross NAT Screening Research Group. Superiority of minipool nucleic acid amplification technology for hepatitis B virus over chemiluminescence immunoassay for hepatitis B surface antigen screening. Vox Sang 2003; 84:287-291.

[7] Kleinman SH, Kuhns MC, Todd DS, Glynn SA, McNamara A, DiMarco A et al. Retrovirus Epidemiology Donor Study. Frequency of HBV DNA detection in US blood donors testing positive for the presence of anti-HBc: implications for transfusion transmission and donor screening. Transfusion 2003; 43:696-704. 
[8] Grob P, Jilg W, Bornhak H, Gerken G, Gerlich WH, Günther S et al. The serological pattern 'anti HBc alone'. Report on a workshop. J Med Virol 2000; 62:450-455.

[9] Hadler SC, Francis DP, Maynard JE, Thompson SE, Judson FN, Echenberg DF et al. Long-term immunogenicity and efficacy of hepatitis B vaccine in homosexual men. N Engl J Med 1986; 315:209-214.

[10] Heermann KH, Goldmann U, Schwartz W, Seyffarth T, Baumgarten H, Gerlich WH. Large surface proteins of hepatitis B virus containing the pre-S sequence. J Virol 1984; 52:396-402.

[11] Neurath AR, Kent SB, Strick N, Parker K. Identification and chemical synthesis of a host cell receptor binding site on hepatitis B virus. Cell 1986; 46:429-436.
[12] Glebe D, Aliakbari M, Krass P, Knoop E, Valerius KP, Gerlich WH. PreS1 antigen dependent infection of Tupaia hepatocyte cultures with human hepatitis B virus. $J$ Virol 2003; 77:9511-9521. [13] Westhoff TH, Jochimsen F, Schmittel A, Stöffler-Meilicke M, Schäfer JH, Zidek W et al. Fatal hepatitis B virus reactivation by an escape mutant following rituximab therapy. Blood 2003; 102:1930

Based on a presentation by Dr Wolfram Gerlich, Institute of Medical Virology, Justus-Liebig University Giessen, Germany.

\section{Hepatitis C in Germany}

A case definition of hepatitis $\mathrm{C}$ has been established by the Robert Koch-Institut based on the provisions of the Infektionsschutzgesetz. (IfSG), Germany's law on prevention and control of communicable diseases. All newly diagnosed cases of hepatitis $\mathrm{C}$ (unless they are already known to be chronic) are notifiable.

Clinical diagnosis is based on elevated transaminases or icterus, and confirmed by laboratory diagnosis through detection of nucleic acid in serum or stool (PCR) or detection of HCV antibodies (e.g., ELISA confirmed with immunoblot).

In 2002, 6,600 cases of hepatitis $\mathrm{C}$ were reported in Germany and classified by strength of evidence, as follows:

\begin{tabular}{|l|c|c|c|c|}
\hline \multirow{2}{*}{ Strength of evidence } & \multicolumn{2}{|c|}{2001} & \multicolumn{2}{c|}{2002} \\
\cline { 2 - 5 } & $\begin{array}{c}\text { Number } \\
\text { of cases }\end{array}$ & $\begin{array}{c}\text { Percentage } \\
\text { of cases }\end{array}$ & $\begin{array}{c}\text { Number } \\
\text { of cases }\end{array}$ & $\begin{array}{c}\text { Percentage } \\
\text { of cases }\end{array}$ \\
\hline $\begin{array}{l}\text { Laboratory + } \\
\text { clinical picture }\end{array}$ & 4,359 & $50.5 \%$ & 2,185 & $33.1 \%$ \\
\hline $\begin{array}{l}\text { Clinical picture + } \\
\text { epidemiological links }\end{array}$ & 0 & $0.0 \%$ & 0 & $0.0 \%$ \\
\hline $\begin{array}{l}\text { Laboratory without } \\
\text { clinical picture }\end{array}$ & 3,012 & $34.9 \%$ & 3,420 & $51.8 \%$ \\
\hline $\begin{array}{l}\text { Laboratory and unknown } \\
\text { clinical picture }\end{array}$ & 1,264 & $14.6 \%$ & 995 & $15.1 \%$ \\
\hline Total 2002, Germany & 8,635 & $100.0 \%$ & 6,600 & $100.0 \%$ \\
\hline
\end{tabular}

Source: Robert Koch-Institut, Infektionsepidemiologisches Jahrbuch 2001 / 2002.

\section{Incidence}

The incidence of hepatitis $C$ in 2002 in Germany was about 8 cases per 100,000 inhabitants. However, as strong laboratory and clinical evidence were available in only $33 \%$ of cases, it is possible that some of the newly diagnosed cases are actually chronic infections.

Incidence by geographical region varies between 1.7 cases per 100,000 inhabitants in Brandenburg and 12.6 cases per 100,000 in Bavaria. There are also relatively high incidence rates in Hessen (11.5), Baden-Württemberg (9.9) and Niedersachsen (9.2).

Eighty-nine percent of HCV cases originated in Germany, and six percent in the Newly Independent States.

\section{Risk groups}

The number of cases by sex was 10.3 for men, and 5.8 for women, peaking between twenty and twenty-nine years of age. The highest risks of infection are among injecting drug users less than fifty years of age $-21 \%$ of cases among males and $13 \%$ of cases among females; among younger age groups below thirty years $-27 \%$ among males and $22 \%$ among females. These data, however, may well be an underestimate, and the actual number of cases of new infections attributed to injecting drug use may be quite higher than reported.

Based on a presentation by Dr Michael Kramer, Federal Ministry of Health and Social Security, Bonn, Germany.

\section{Hepatitis C virus infection in medical settings}

Since the introduction of blood donor screening and viral inactivation of plasma-derived products, transfusion-related transmission of hepatitis $\mathrm{C}$ virus has virtually been eliminated. In the industrialised countries, currently most $\mathrm{HCV}$ infections can be attributed to risk factors identified in cohort studies and casecontrol investigations of acute hepatitis $\mathrm{C}$ disease. According to data from the Centers for Disease Control and Prevention (CDC) [1], most newly acquired cases of HCV infection are associated with drug abuse (68\%) and sexual contacts with an infected partner
(18\%). The source of infection remains unknown in $9 \%$ of cases and occupational, nosocomial, iatrogenic, and perinatal exposures all together account for about $5 \%$ of new HCV infections.

\section{Nosocomial HCV infection}

Despite a decrease in the prevalence and incidence of $\mathrm{HCV}$ infection over the last ten years, new infections in haemodialysis settings still occur and in most cases the virus transmission can be attributed to accidental or inadvertent breaches of standard 
universal precautionary measures. Most new HCV infections in haemodialysis units nowadays are caused by patient-to-patient spread of the virus rather than by transmission via contaminated dialysis equipment.

There are several reports indicating that nosocomial HCV infection might represent a substantial problem not only for haemodialysis patients but also for other groups of immunosuppressed patients, for instance, those treated in oncology wards. In a recent study [2], at least 66 new $\mathrm{HCV}$ infections were diagnosed among patients on a paediatric oncology ward between 1998 and 2000. Comprehensive epidemiological and molecular analyses were performed to determine the possible source and route of transmission. Transmission of HCV by blood, blood products or from HCV-infected health-care workers $(\mathrm{HCW})$ was excluded. However, numerous breaches of standard infection control procedures were detected. In the autumn of 2000, universal precautions were put into effect and adherence to the hygienic guidelines was specially monitored. One such preventive measure was to abolish multi-dose medication vials. The implemented measures reduced the incidence of infections significantly. These data indicate that the spread of the $\mathrm{HCV}$ in this setting most probably could have been prevented by following universal precautions in infection control.

The prevalence of HCV infection among HCWs is not significantly higher than in the general population. This indicates that the risk of HCWs being infected by HCV is lower than the probability of acquiring HBV in medical settings. However, there is still a substantial residual risk of occupational $\mathrm{HCV}$ infection. In Germany, 140 to 250 cases of HCV infection were reported every year between 1995 and 1999 to the occupational health insurance of German HCWs, and 40 to 90 cases were finally considered to be occupational HCV transmission [3]. Breakdown of all reported cases by profession demonstrated that among HCWs mostly nurses $(58 \%)$ were affected, followed by doctors $(12.7 \%)$. Assistants and laboratory workers were affected to a lesser extent $(10.1 \%$ and $4.4 \%$, respectively). Thus, all medical personnel should continually be aware of the risk of bloodborne pathogens spread in medical settings [4].

Among the devices that are associated with percutaneous injuries in Germany, needles make up approximately $65 \%$ of the total, scalpels $12 \%$, and other sharps $23 \%$ [3]. Some of the prevention measures to avoid such injuries might include the use of needle shields and self-blunting needles, as shown below.

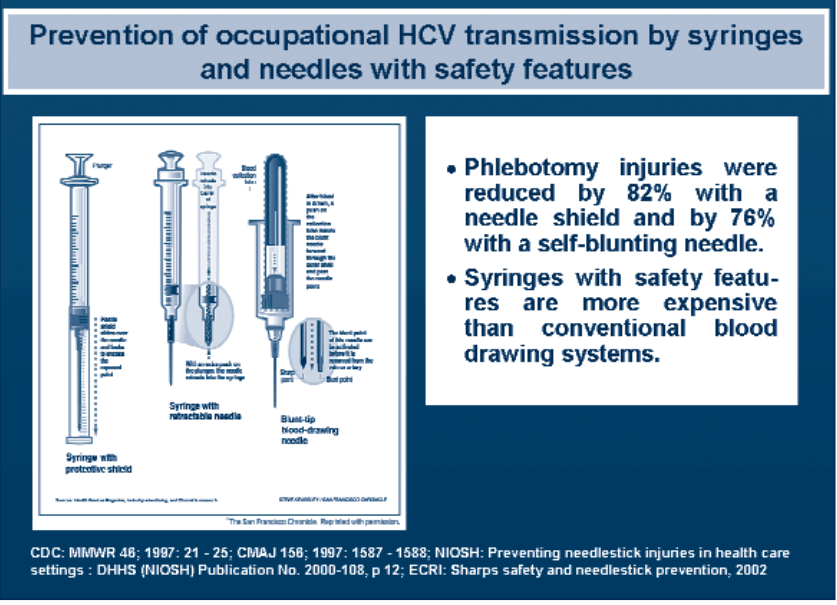

During in vitro tests and animal experiments, sterile (virucidal) gloves consisting of two layers of latex and an intermediate emulsion of disinfectant have been tried. Application of virucidal gloves in experiments with enveloped viruses (BVDV and FIV) resulted in an approximate 15-fold reduction of infectivity, and in animal experiments infection rates could be reduced by more than $50 \%$. However, virucidal gloves have not yet been evaluated in clinical practice [5].

\section{HCV transmission from infected medical staff to patients}

There are ongoing and controversial discussions within the medical community concerning the number of $\mathrm{HCV}$ infections being transmitted by infected medical staff to their patients, and the implications this may have for public health.

\begin{tabular}{|c|c|c|c|c|c|}
\hline Case & HCW & $\begin{array}{l}\text { RNA } \\
\text { Titre }\end{array}$ & $\begin{array}{l}\text { Patients Tested } \\
\text { for } \mathrm{HCV} \text { (N) }\end{array}$ & $\begin{array}{l}\text { Transmission } \\
\text { Rate (N, [\%]) }\end{array}$ & Reference \\
\hline 1 & $\begin{array}{l}\text { Cardiothoracic } \\
\text { surgeon }\end{array}$ & $\begin{array}{l}2 \times 10^{7} \\
\mathrm{GE} / \mathrm{ml}\end{array}$ & 222 & $5 / 222(2.3)$ & $\begin{array}{l}\text { Esteban et } \\
\text { al., 1996 }\end{array}$ \\
\hline 2 & $\begin{array}{l}\text { Cardiothoracic } \\
\text { surgeon }\end{array}$ & $\begin{array}{l}>10^{6} \\
\mathrm{GE} / \mathrm{ml}\end{array}$ & 278 & $1 / 278(0.36)$ & \begin{tabular}{|l} 
Duckworth \\
et al., 1999
\end{tabular} \\
\hline 3 & Gynaecologist & $?$ & 4500 & $8 / 4500(0.18)$ & NN, 2000 \\
\hline 4 & Surgeon & $?$ & 1900 & $3 / 1900(0.16)$ & \begin{tabular}{|l|} 
NN, 2000 \\
\end{tabular} \\
\hline 5 & Surgeon & $?$ & 732 & $1 * / 732(0.14)$ & NN, 2000 \\
\hline 6 & $?$ & $?$ & 228 & $1^{\star} / 228(0.44)$ & NN, 2001 \\
\hline 7 & Anaesthesiologist & $\begin{array}{l}3.8 \times 10^{7} \\
\mathrm{IU} / \mathrm{ml}\end{array}$ & 348 & $1 / 348(0.29)$ & $\begin{array}{l}\text { Cody et al., } \\
2002\end{array}$ \\
\hline 8 & Gynaecologist & $\begin{array}{l}2.7 \times 10^{5} \\
\mathrm{IU} / \mathrm{ml}\end{array}$ & 2286 & $1 / 2286(0.04)$ & $\begin{array}{l}\text { Ross et al., } \\
2002\end{array}$ \\
\hline 9 & $\begin{array}{l}\text { Orthopaedic } \\
\text { surgeon }\end{array}$ & $\begin{array}{l}1.3 \times 10^{6} \\
\mathrm{IU} / \mathrm{ml}\end{array}$ & 207 & $1 / 207(0.48)$ & \begin{tabular}{|l} 
Ross et al., \\
2002
\end{tabular} \\
\hline \multirow[t]{2}{*}{10} & $\begin{array}{l}\text { Orthopaedic } \\
\text { surgeon }\end{array}$ & ? & 1068 & 0/1068 & $\begin{array}{l}\text { Ross et al., } \\
2003\end{array}$ \\
\hline & & & 11769 & $22 / 11769(0.19)$ & \\
\hline
\end{tabular}

Thus far, only a few case reports [6-8] have been published on provider-to-patient transmission of $\mathrm{HCV}$, and it is clear that further studies need to be carried out to assess more precisely the real risk of such transmission.

No consensus on the management and guidance of HCWs infected with HCV has been reached so far on an international level. In the United States, for example, no restrictions are imposed upon infected medical staff until a transmission is proved. Germany [9], England, and Canada, however, have adopted a more conservative approach and have set some restrictions on exposure-prone procedures (EPP) performed by infected health-care workers.

\section{Conclusions}

Nosocomial and iatrogenic HCV infections still occur in a variety of medical settings. Nosocomial infections of patients with $\mathrm{HCV}$ due to health-care procedures other than haemodialysis have been reported and were mostly associated with breaches of standard infection control precautions. The available data point to the need for a continuous monitoring of infection control measures as well as increased awareness among health-care workers of the potential risks of nosocomial HCV transmission.

\section{References}

[1] Alter MJ. Prevention of spread of hepatitis C. Hepatology 2002; 36(Suppl 1):S93-S98.

[2] Dumpis U, Kovalova Z, Jansons J, Cupane L, Sominskaya I, Michailova M et al. An outbreak of HBV and HCV infection in a paediatric oncology ward: epidemiological investigations and prevention of further spread. J Med Virol 2003; 69:331-338.

[3] Ross S, Roggendorf M. Epidemiologie der Hepatitis CInfection und das Problem nosocomialer Übertragungen durch infiziertes medizinisches Personal. In: Mauss S, Rockstroh JK, Jager H: Koinfektion Hepatitis und HIV. Stuttgart. Thieme, 2002, 1-8. 
[4] Ross RS, Niederau C, Viazov S, Schreier E, Heberer J, Häussinger $\mathrm{D}$ et al. Begutachtungsfragen bei acuter und chronischer Hepatitis C. In: Häussinger, Niederau (Eds.). Hepatitis C. Berlin. Blackwell, 2001, 347-373.

[5] Bricout F, Moraillon A, Sonntag P, Hörner P, Blackwelder W, Plotkin S. Virus-inhibiting surgical glove to reduce the risk of infection by enveloped viruses. J Med Virol 2003; 69:538-545.

[6] Heptonstall J. Surgeons who test positive for hepatitis C should be transferred to low risk duties. Rev Med Virol 2000; 10:75-78.

[7] Cockcroft A. Surgeons who test positive for hepatitis C should not be transferred to low risk duties. Rev Med Virol 2000;10:79-82. [8] Ross RS, Viazov S, Roggendorf M. Risk of hepatitis C transmission from infected medical staff to patients: model-based calculations for surgical settings. Arch Intern Med 2000; 160:2313-2316.

[9] Robert Koch-Institut. Empfehlungen zur Verhütung der Übertragung von Hepatitis-C-Virus durch infiziertes Personal im Gesundheitsdienst. Epidemiologisches Bulletin 2001; 3:15-16. http://www.rki.de/INFEKT/EPIBULL/2001/3TEXT_01.PDF

Based on a presentation by Dr Sergei Viazov, University of Duisburg-Essen, Institute of Virology, Essen, Germany. Figures were provided by Dr. Stefan Ross, University of Duisburg-Essen, Institute of Virology, Essen, Germany.

\section{Follow-up of iatrogenic hepatitis $C$ virus infections related to anti-Rh prophylaxis}

During 1978 and 1979, an outbreak of hepatitis C occurred in the German Democratic Republic following administration of anti-D immunoglobulin that had been contaminated with hepatitis $C$ virus (genotype 1b) [1]. Fourteen infected batches were given to 6,735 women; subsequently, 2,533 were identified with elevated ALT levels that became evident during a twenty-five week period of screening carried out at public health centres.

A cohort of 1,018 of the involved women was examined. Within 6 months after anti-D administration, $10 \%$ of them had no evidence of disease and $90 \%$ had acute hepatitis C $(\mathrm{n}=917)$. Among these 917 affected women, all of whom were monitored during a twentyyear period following infection with $\mathrm{HCV}$, only $0.4 \%$ developed cirrhosis. Other results showed the following:

- $85 \%$ were anti-HCV positive

- $55 \%$ had a persistent viraemia

- approximately $67 \%$ showed symptoms

- $0.2 \%$ died from liver disease

From 106 of the HCV-infected women (mean age approximately twenty-four years), 1,368 sera were collected over a period of seventeen years (1978-1995). The data revealed that $16 \%$ of them were asymptomatic, $39 \%$ had acute self-limited infection, and $45 \%$ had progressed to chronic infection. The results further included:

(1) Patients with symptomatic acute hepatitis

- $46 \%$ spontaneous recovery; within 4 months loss of HCV RNA

- $54 \%$ developed (mild to moderate) chronic hepatitis

- mild fibrosis, no cirrhosis after 17 years

- elevated transaminases and HCV RNA in more than 50\%

(2) Patients with asymptomatic acute HCV infection

- in $94 \%$ only anti-HCV detectable

- HCV RNA + anti-HCV in only one patient (6\%)

(3) Loss of serological markers after 15 years

- in $>30 \%$ of patients with asymptomatic and acute self-limited infection no serological HCV markers detectable (ELISA)

- in $>60 \%$ no / indeterminate serological HCV markers (ELISA, Blot)
The latter study concluded that among women who are infected at an early age, the course of $\mathrm{HCV}$ infection is relatively slow. In this cohort of 106 women, no cirrhosis, HCC, or death related to chronic hepatitis was observed during a twenty-year period after the infection. In contrast to this, in cases where alcohol abuse or co-infection with HIV or HBV is present, these pathologies are evident within twenty years following infection.

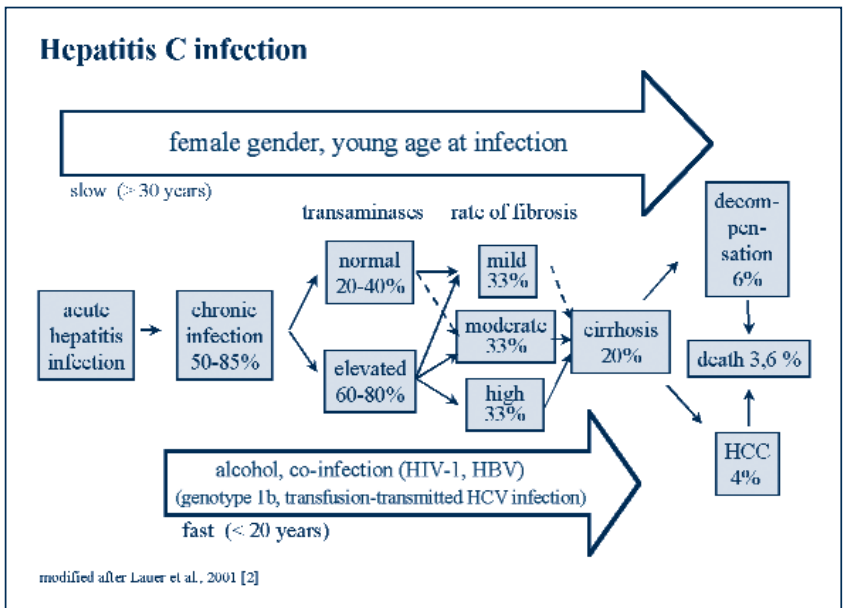

The conclusions of this study suggest that further data are still needed in order to examine the relationship between the age of $\mathrm{HCV}$-infected patient at the onset of disease and the disease outcome.

\section{References}

[1] Wiese M, Berr F, Lafrenz M, Porst H, Ösen U. Low frequency of cirrhosis in a hepatitis $\mathrm{C}$ (genotype $1 \mathrm{~b}$ ) single-source outbreak in Germany: a 20-year multicenter study. Hepatology 2000; 32:9196.

[2] Lauer GM, Walker BD. Hepatitis C virus infection. $N$ Engl $J$ Med 2001; 345:41-52.

Based on a presentation by Dr Anne-Sophie Endres and Dr Helga Meisel, Universitätsklinikum Charité, Berlin, Germany. 


\section{School-entry monitoring of vaccination status}

Germany's infection protection law (Infektionsschutzgesetz) requires that local public health offices record the vaccination status of all children entering the first class of a primary school. This information is then sent to the Robert Koch-Institut as anonymous, aggregated data in order to protect the privacy of each child. However, parents are not obliged to cooperate, and the provision of vaccination certificates is voluntary.

During the 2000-2002 period, 757,125 children were seen at school entry vaccinations in Germany (no data from Hamburg, Bremerhaven, and Sachsen). Vaccination certificates could be evaluated for 681,561 children $(90 \%)$. The certificates provided information on the vaccination status against diphtheria, tetanus, pertussis, Haemophilus influenzae type b disease, poliomyelitis, hepatitis $\mathrm{B}$, and one dose against measles, mumps and rubella. Hepatitis B vaccine coverage for this period for Germany was approximately $67 \%$. However, there are wide differences in coverage by region as well as by nationality.

In Bavaria, the Public Health Office figures for 2002 showed hepatitis B vaccination coverage lower than $40 \%$ in some areas (e.g., Rosenheim and Bad Tölz-Wolfratshausen), and other areas as high as $90 \%$ (Hof and Kronach).

In Baden-Württemberg, hepatitis B vaccination coverage increased dramatically between 1997 , which was approximately $10 \%$ when the vaccine was first introduced, and 2002, when it had risen to approximately $70 \%$.

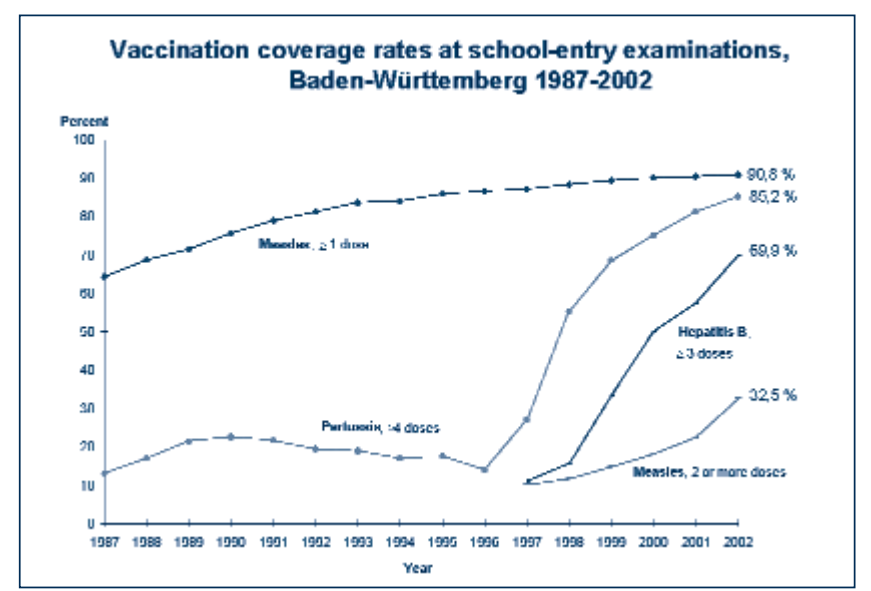

Among the various nationalities of children in Baden-Württemberg with vaccination certificates at school-entry, Germany and the former Yugoslavia have the highest percentages - approximately $93 \%$ and $91 \%$, respectively - compared with other nationalities.

\begin{tabular}{|c|c|}
\hline \multicolumn{2}{|c|}{$\begin{array}{c}\text { Percentage of children with vaccination certificate } \\
\text { at school-entry examinations, by nationality, } \\
\text { Baden-Württemberg, } 2003\end{array}$} \\
\hline Nationslity & provided by... \\
\hline (ierman & $9,3,1$ \\
\hline 'lurkish & 81,6 \\
\hline Italian & 88,7 \\
\hline (ireek & 82,5 \\
\hline l'опист YU & 90,5 \\
\hline Other & 79,5 \\
\hline $\begin{array}{l}\text { Provisional data from } 32 \text { / } 38 \text { regional } \\
\text { public health offices as of Coctober 12, } 2003\end{array}$ & $\angle G_{n}^{A}$ \\
\hline
\end{tabular}

Hepatitis B vaccination coverage among adolescents is lagging behind younger age groups. This may be attributed to the fact that children over the age of ten or eleven were born before the hepatitis B vaccine was officially recommended in Germany's immunisation schedule. Surveys show, however, that hepatitis B vaccination coverage among adolescents is catching up.

Hepatitis A vaccination is not generally recommended in the paediatric immunisation schedule, and coverage is low. In BadenWürttemberg in 2003, native German children had a low hepatitis A vaccination coverage $(5.5 \%)$ at school-entry compared with Turkish children, who had the highest hepatitis A vaccination coverage $(9.2 \%)$ of all nationalities.

Since the infection protection law took effect in 2000, Germany is able to generate reliable nationwide vaccination coverage data, with public health offices providing information on where compliance is lacking on a regional basis, and where catch-up campaigns need to be implemented for those children and adolescents who may have missed a vaccination opportunity.

Based on a presentation by Dr Günter Pfaff, Landesgesundheitsamt Baden-Württemberg, Abteilung Epidemiologie und Gesundheitsberichterstattung, Stuttgart, Germany.

\section{Critical review of programme progress}

Germany's new comprehensive communicable disease law, the Infektionsschutzgesetz. (IfSG), has resulted in a significantly improved case-based surveillance system that takes into account fifteen notifiable diseases, more than fifty pathogens, and standardised, EU-compatible case definitions that must be used by local health departments.

\section{Streamlined surveillance systems and reporting channels}

Streamlined reporting channels via electronic transmission and databases are available at all levels for local interventions, detecting national trends, and programme assessment. Specialised software applications (such as SurvNet) power the surveillance networks and allow for a rapid flow of information and interaction among laboratories, state and local health departments, and the Robert Koch-Institut at national level. Weekly electronic publication of data is made available through Germany's Epidemiologisches Bulletin.

Despite these advances, there is still under-reporting by physicians and diagnostic laboratories.

\section{STIKO recommendations}

Vaccine recommendations continue to be made by the Ständige Impfkommission (STIKO) - the German advisory committee on vaccination practices -whose specific tasks are defined in the new law. 
German vaccination recommendations cover the following groups:

- Infants and adolescents - universal

- Adults and risk groups (in line with international standards)

- Health-care professionals

- Individuals with underlying illnesses

- Other risk groups

In 2000, two new hexavalent vaccines containing the hepatitis B component came onto the German market, resulting in high uptake due to their rapid acceptance by physicians as well as parents of young children.

STIKO recommendations are not legally binding on the Federal States (Länder) or by physicians. The health authorities of the States take the decision on which vaccines are to be made publicly recommended, and physicians then implement the recommendations. Publicly recommended vaccines need to be agreed upon with the health insurance companies before compensation is allowed.

There is often some time lag between the issuing of a new or revised STIKO recommendation and its implementation due to the amount of time needed for the information to reach physicians and the publication of this information in medical journals.

\section{Health-care services}

Germany's health-care system delivers its services via the following:

- Paediatricians in private practice

- General practitioners

- Gynaecologists and other specialists in private practice

- Hospitals

- Public health services

Social health insurance provides medical services through physicians and hospitals free of charge with some co-payments for the patients, and covers $90 \%$ of the entire German population. The rest hold contracts with private health insurance companies.

Vaccination is carried out by the treating physician, resulting in fewer missed immunisation opportunities. However, as there are many players in the health-care system, debate continues as to whether the role of the public health services should be strengthened with the aim of achieving 95\% coverage for all vaccinations.

\section{Monitoring systems}

- Monitoring systems via checking of vaccination certificates show that vaccine coverage is rising quickly among children at school-age entry (six years).

- Seroprevalence surveys are providing valuable information on hepatitis B seroprevalence among the general population in Germany.

- While morbidity and mortality data are available, the quality of information provided on death certificates needs to be improved.

- Hospitalisation data are accessible allowing enhanced monitoring of acute and chronic cases of hepatitis.

- New investigative teams have been set up at the Robert KochInstitut in Berlin to evaluate disease outbreaks.

\section{Limitations}

- The current monitoring system only assesses coverage data at school-age entry of six years and not at the target age of two years.

- Due to data protection law in Germany, no vaccine registry exists.

- There are limitations regarding supplemental data (e.g., whether an individual belongs to a risk group), due to data protection law.

- Vaccine coverage remains relatively low among adolescents and adults in risk groups, and more information is still needed on compliance.

\section{Screening pregnant women}

A universal screening programme for pregnant women has been in place since 1994. Compliance is approximately $80 \%$, raising questions as to whether screening should take place earlier than 32 weeks into pregnancy. Newborns of women who test positive for $\mathrm{HBsAg}$ receive HBIg and active immunisation. Contact tracing of infected family members or partners, which is carried out at local levels, remains weak.

\section{Other issues}

Criteria have been established for definitions of adverse events (AE) following immunisation, known in German law as 'complication after vaccination,' or suspected adverse health effects exceeding normal reaction to vaccination. A vaccination certificate is a legal requirement to receive compensation, and the AE must be reported within 24 hours. The hierarchical notification system, involves reporting by the following organisations:

$$
\begin{aligned}
& \Rightarrow \text { local health department must report AE within } 24 \text { hours } \\
& \Rightarrow \text { State health department } \\
& \Rightarrow \text { Paul Ehrlich-Institut, and } \\
& \quad \Rightarrow \text { Robert Koch-Institut }
\end{aligned}
$$

Other issues under discussion include compensation for complications after vaccination, and vaccine safety and effectiveness. Weaknesses also exist within Germany's school system, which lacks an infrastructure that can provide medical information to its students. Creating a medical school-based team of doctors, nurses, and midwives would provide the necessary human resources for instruction in disease prevention.

Based on a joint presentation by Dr Johannes Hallauer, Gesundheitssystemforschung, Universitätsklinikum Charité, Berlin, Germany, and Dr Michael Kramer, Federal Ministry of Health and Social Security, Bonn, Germany 


\section{Conclusions of the meeting}

The Viral Hepatitis Prevention Board convened a meeting of international experts from the public and private sectors in the Nordic countries and Germany, October 13-14, 2003 in Berlin, Germany. The objectives of the meeting were to review and evaluate viral hepatitis prevention and control measures in Denmark, Finland, Iceland, Norway, Sweden, and Germany. These evaluations were based on information provided by the participants, and included:

- the latest epidemiological data for viral hepatitis in the Nordic countries and Germany;

- surveillance systems for infectious diseases including monitoring of adverse events following hepatitis B vaccination;

- successes as well as challenges of the Nordic and German experiences, and how to move forward in preventing and controlling viral hepatitis.

\section{THE NORDIC COUNTRIES}

\section{Hepatitis A in the Nordic countries}

All of the Nordic countries, with the exception of Iceland, reported hepatitis A outbreaks among injecting drug users in recent years. One of the reasons for these outbreaks is the dramatic increase in non-immune drug users that has been reported over the years in many of the Nordic countries. Other outbreak sources can be traced to persons who were infected with HAV within families, day-care centres, and other living situations. Very few cases of HAV infection in Sweden have been acquired in Africa, suggesting that Swedish travellers are well vaccinated before departure. For the last ten years, molecular genotyping has been used to identify individual outbreaks of hepatitis A and to determine the infection source.

\section{Hepatitis B in the Nordic countries}

Hepatitis B is a notifiable disease in all of the Nordic countries, all of which report acute and chronic hepatitis, with the exception of Finland, which makes no differentiation between acute and chronic cases. The main measures for hepatitis B prevention in the Nordic countries are: (1) pre-exposure and post-exposure immunisations; (2) testing in pregnancy; and (3) harm-reduction measures among injecting drug users. All Nordic countries apply risk-group hepatitis B vaccination. However, policies vary by country with regard to specific risk groups targeted for immunisation, reimbursement, and harmreduction measures among injecting drug users.

\section{Hepatitis B epidemiology}

In 2002, the incidence of acute hepatitis B per 100,000 inhabitants was relatively high in Norway, Finland, and Sweden, and extremely high in the northwest Russian border regions. These high incidence rates are mainly caused by outbreaks among injecting drug users and their sexual partners.

\section{Immunisation}

In all of the Nordic countries, injecting drug users are the main group recommended for vaccination. Male homosexuals are a target group only in Denmark, Norway and Sweden. Employees in high-risk occupations, such as some health-care workers, prison staff and the police, are also regarded as a target group for vaccination in all Nordic countries. Medical students, however, are not covered, as they are not considered officially employed. Most medical conditions warranting hepatitis B vaccination are covered by most of the countries. However, some risk groups, such as dialysis patients, are recommended for vaccination only in Norway and Sweden. Norway also has one of the most extensive immunisation programmes for immigrants from high-endemic areas, including their newborns.

\section{Reimbursement}

There are wide variations in reimbursement policies not only by country but also locally by region. Some vaccines are free and covered by the State, others are free but covered by regional authorities, and some are free or paid by employers.

\section{Harm-reduction measures among injecting drug users}

There is a restrictive drug policy in all of the Nordic countries that bans the possession, use and trafficking of drugs. Measures to reduce demand and supply of drugs are therefore still the basis of prevention strategy in all the Nordic countries. The question of harm reduction measures is more controversial. While extensive free needle and needle exchange programmes or both are in use in Norway, Denmark and Finland, this is not generally the case in Sweden or Iceland. Clean needles and syringes are, however, available at pharmacies in all the countries. In Sweden, syringes can only be obtained by prescription from a doctor. Likewise, Sweden is more restrictive in offering drug-assisted treatment (like methadone and buprenorfin) than the other countries.

\section{HBsAg-positive children in Swedish day-care centres}

Sweden's 1991 recommendations concerning HBsAg-positive children in day care are vague and ambiguous, and have resulted in a lack of consensus among its twenty-one counties on how the recommendations are to be interpreted and implemented. Sweden's present recommendations are not in keeping with prevention measures that have been adopted in most European Union Member States, and with the WHO recommendation to include hepatitis $\mathrm{B}$ vaccine in national universal immunisation schedules. Implementing universal hepatitis B immunisation would help to resolve many issues that are linked to high costs and amount of time in contact tracing during hepatitis B outbreaks in day-care centres, and to ethical issues surrounding carriers and their contacts, while protecting all children regardless of ethnic background from HBV infection.

\section{Nosocomial transmission of hepatitis B in Sweden}

Nosocomial transmission of HBV is rare in Sweden. Data from the Swedish National Institute for Infection Control show a dramatic decrease since 1985 of HBV infections in staff from medical, dental, laboratory, and other related settings. However, assessment of a small cluster of cases in a hospital setting in Sweden revealed that a number of prevention measures had not been implemented. Furthermore, 50\% of the hospital staff that report injuries from needle sticks and sharps are unvaccinated against $\mathrm{HBV}$ infection, a situation that points to the need for mandatory hepatitis B vaccination for persons at occupational risk of $\mathrm{HBV}$ infection. 


\section{GERMANY}

\section{Germany's health-care system}

Recent demographic trends in Germany show an ageing population requiring long-term health care. This, combined with increasingly low birth rates and high levels of unemployment, has led to calls for reform. Currently there is also a huge imbalance between expenditures for prevention and for treatment of infectious diseases. There is a pressing need to carry out economic evaluations of preventive interventions that can be used at political levels to redress this imbalance. The various elements of the health-care system often lack interaction, although there are attempts to close some of the gaps.

\section{The Infektionsschutzgesetz.}

Germany's law on prevention and control of communicable diseases, the Infektionsschutzgesetz (IfSG), which went into effect in January 2001, has resulted in a significantly improved case-based surveillance system that takes into account fifteen notifiable diseases, more than fifty pathogens, and standardised, EU-compatible case definitions that must be used by local health departments.

\section{Surveillance and monitoring}

Since the Infektionsschutzgesetz took effect, Germany has been able to generate reliable nationwide vaccination coverage data, with public health offices providing information on where compliance is lacking on a regional basis, and where catch-up campaigns need to be implemented for children and adolescents who may have missed a vaccination opportunity.

Streamlined reporting channels via electronic transmission and databases are available at all levels for local interventions, detecting national trends, and programme assessment, as well as other data derived from: (1) monitoring systems via checking of vaccination certificates showing that vaccine coverage is rising quickly among children at school-age entry (six years); (2) seroprevalence surveys providing information on hepatitis B prevalence among the general population; (3) morbidity and mortality data (while these data are available, the quality of information provided on death certificates needs to be improved); (4) hospitalisation data allowing enhanced monitoring of acute and chronic cases of viral hepatitis; and (5) new investigative teams at the Robert Koch-Institut to evaluate disease outbreaks.

Despite these advances, there is still under-reporting by physicians and diagnostic laboratories. Other limitations relate to: (a) the current monitoring system, which only assesses coverage data at school-age entry and not at the target age of two years; (b) lack of a vaccine registry due to data protection law in Germany; (c) supplemental data (e.g., whether an individual belongs to a risk group) due to data protection law; (d) relatively low vaccine coverage among adolescents and adults in risk groups; and (e) compliance data.

\section{Vaccine recommendations}

Vaccine recommendations continue to be made by the Ständige Impfkommission (STIKO), whose specific tasks are defined in the new law. German vaccination recommendations cover the following groups: (1) infants and adolescents - universal; (2) adults and risk groups (in line with international standards).

\section{Adverse events following immunisation}

Criteria have been established for definitions of adverse events following immunisation, known in German law as 'complication after vaccination,' or suspected adverse health effects exceeding normal reaction to vaccination. A vaccination certificate is a legal requirement to receive compensation, and the event must be reported within 24 hours.

\section{Education, training, and resources}

Weaknesses exist within Germany's school system, which lacks an infrastructure that can provide medical information to its students. Efforts should be made to integrate education, life style, and vaccination in order to achieve high coverage. Efforts could be made to create a medical school-based team, administering vaccines, providing medical information, and checking and documenting the vaccination status of students.

\section{Social health insurance}

Social health insurance provides medical services through physicians and hospitals free of charge with some copayments for the patients, and covers $90 \%$ of the entire German population. The rest hold contracts with private health insurance companies.

\section{Hepatitis A in Germany}

Hepatitis A is a notifiable disease, as specified by the Infektionsschutzgesetz. Clinical diagnoses are reported by physicians; acute infections must be reported by laboratories. A case definition for hepatitis A in Germany (updated on 1 January 2004) has been established, which allows for a standardisation and differentiation of the reported cases. EU case definitions are taken into account. Information on whether an individual belongs to a risk group is not available in the surveillance data, and contact tracing remains the responsibility of local health departments.

\section{Hepatitis A epidemiology}

The notified incidence of cases of hepatitis A virus infection in Germany shows a marked decline since 1980, particularly in the east. In 2002, there was a higher incidence in the western States and the City-states of Berlin, Bremen, and Hamburg.

There is a clear seasonal pattern, with more cases of HAV infection occurring after the end of the summer holidays. The incidence of cases of HAV infection by gender and age group for the year 2002 is highest among the younger age group of five to nine years. The prevalence of anti-HAV antibodies is highest among those in older age groups, a consequence of a cohort effect.

\section{Hepatitis A outbreaks}

With decreasing seroprevalence in the younger age cohorts, the risk for outbreaks is increasing. As outbreak investigations require human resources, Germany will need to continue to train more field epidemiologists as experts in outbreak management. International collaboration can be fundamental for the discovery and the study of outbreaks, and should be further enhanced. 


\section{Hepatitis A immunisation}

Hepatitis A vaccination is not generally recommended in Germany's paediatric immunisation schedule, and coverage is low.

\section{Hepatitis B in Germany}

Hepatitis B has been a notifiable disease in Germany since 1980 in West Germany, and since 1983 in the east. A case definition was established in 2001 by the IfSG, based upon a clinical picture together with laboratory findings for acute cases. Also reportable are positive laboratory findings where the symptoms are either absent or unknown.

\section{Hepatitis B epidemiology}

Hepatitis B incidence rates have been declining in Germany since 1993 . Notification data for 2002 by gender and age group show that the highest incidence of hepatitis $\mathrm{B}$ is among females between twenty and twenty-four years, and males between twenty-five and twenty-nine years, with decreasing incidence among older age groups for both genders. The overall prevalence of anti-HBc antibodies increases with age, with higher prevalence in western States than in the east.

\section{Hepatitis B outbreaks}

Hepatitis B outbreaks are rare in Germany. Sporadically occurring clusters of cases seem to be attributed to breaches in hygiene in long-term care facilities and dialysis centres.

\section{Hepatitis B mortality rates}

Hospitalisation data for the period 1998 to 2001 show that the number of deaths due to hepatitis increased among patients with chronic infection and decreased slightly for acute cases of hepatitis B and unspecified hepatitis.

\section{Hepatitis B risk groups}

In Germany, four main risk groups are candidates for hepatitis B vaccination: medical staff; men who have sex with men; injecting drug users; and haemodialysis patients. Other groups considered at risk for HBV infection are heterosexuals with multiple sex partners, travellers to areas of high hepatitis B endemicity, immigrants and refugees from such areas, household contacts and sex partners of HBV carriers, prison inmates and staff, and clients and staff in institutions of the mentally disabled. Notification data for 2002 show that the highest proportion of reported exposures for $\mathrm{HBV}$ is among those engaging in heterosexual intercourse.

\section{Hepatitis B immunisation}

By the early 1990s, many at-risk individuals were still not being vaccinated against hepatitis $B$ and in view of the increase in the number of HBV infections, Germany's hepatitis $B$ vaccination strategy was beginning to be re-examined. In 1995, the STIKO issued new recommendations for universal hepatitis B vaccination for infants, children, and adolescents, together with the previous recommendations for risk groups.

The low hepatitis B vaccination coverage in adolescents illustrates that adolescents as well as teachers do not have a clear understanding of the necessity of prevention. Therefore, there is a need to enhance uptake levels by providing information on vaccination and by making outreach efforts. An accelerated hepatitis B vaccination schedule is recommended for travellers to high-endemic areas and for drug users.

\section{Screening pregnant women for hepatitis $B$}

Newborns infected with HBV have a $25 \%$ lifetime risk of primary hepatocellular carcinoma or cirrhosis. Since highrisk screening criteria can miss a substantial proportion of HBsAg-positive women, Germany revised its screening regulations in 1994 to extend HBsAg testing to all pregnant women. Compliance is approximately $80 \%$, raising questions as to whether screening should take place earlier than 32 weeks into pregnancy, as is done for rubella.

Newborns of women who test positive for HBsAg receive both HBIg and active hepatitis B immunisation at birth. Contact tracing of infected family members or partners, which is carried out at local levels, remains weak.

\section{Wild-type $H B V$ and $H B V$ escape mutants}

Escape mutants of HBV continue to be found in Germany. However, although potentially pathogenic, they are unlikely to pose a public health problem in the near future.

\section{Hepatitis C in Germany}

\section{Nosocomial transmission}

Despite a decrease in the prevalence and incidence of HCV infection over the last ten years, new infections in haemodialysis settings still occur. In most cases, transmission occurs by patient-to-patient spread of the virus rather than via contaminated dialysis equipment.

The prevalence of $\mathrm{HCV}$ infection among HCWs is not significantly higher than in the general population and lower than in medical settings. However, there is still a substantial residual risk of occupational $\mathrm{HCV}$ infection. Needles make up approximately $65 \%$ of the total percutaneous injuries in Germany. No consensus on the management and guidance of HCWs infected with $\mathrm{HCV}$ has been reached so far on an international level. Germany has set some restrictions on exposure-prone procedures performed by infected HCWs.

The available data point to the need for a continuous monitoring of infection control measures as well as increased awareness among health-care workers of the potential risks of nosocomial HCV transmission.

\section{Long-term course of HCV infection}

Several studies indicated that the long-term course of HCV infection is relatively slow, except in cases where alcohol abuse or co-infection with HIV or HBV is present. 


\section{List of participants}

\begin{tabular}{llll} 
Dr Katharina Alpers & Germany & Dr Daniel Lavanchy & Switzerland \\
Dr Selim Badur & Turkey & Dr Marie-Liesse LeCorfec & France \\
Dr Ulrich Bienzle & Germany & Dr Andrei Lobanov & Denmark \\
Dr Hans Blystad & Norway & Dr Harold Margolis & USA \\
Dr Paolo Bonanni & Italy & Dr André Meheus & Belgium \\
Dr Claire Bramley & United Kingdom & Dr Hanne Nøkleby & Norway \\
Dr Uwe Büsching & Germany & Dr Günter Pfaff & Germany \\
Dr Norbert De Clercq & Belgium & Dr Doris Radun & Germany \\
Mr David FitzSimons & Switzerland & Dr Lars Rombo & Sweden \\
Dr Guido François & Belgium & Dr Françoise Roudot-Thoraval & France \\
Dr Wolfram Gerlich & Germany & Dr Daniel Shouval & Israel \\
Dr Peter Grob & Switzerland & Ms Diana Steimle & Belgium \\
Dr Nicole Guérin & France & Dr Johan Struwe & Sweden \\
Dr Johannes Hallauer & Germany & Dr Pierre Van Damme & Belgium \\
Dr Wolfgang Jilg & Germany & Dr Sergei Viazov & Germany \\
Dr Mark Kane & USA & Mr Alex Vorsters & Belgium \\
Dr Michael Kramer & Germany & Dr Steven Wiersma & Switzerland \\
\hline
\end{tabular}

\section{VHPB e-mail service}

Please visit our updated website (www.vhpb.org) and register to receive recent information on the VHPB and its newsletter, Viral Hepatitis. You will then be informed by e-mail when new issues of Viral Hepatitis or other information become available on the website.

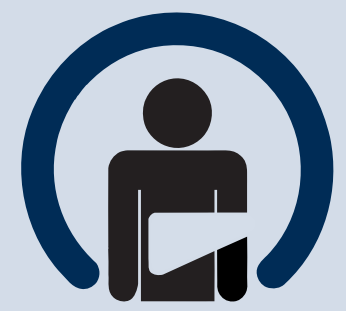

(C)The Viral Hepatitis Prevention Board All rights reserved.

No part of this publication may be reproduced, stored in a retrieval system or transmitted, in any form or by any means, electronic, mechanical, photocopying, recording or otherwise, without prior written permission of the publisher.
The Viral Hepatitis Prevention Board (VHPB) is supported by grants from the pharmaceutical industry (GlaxoSmithKline Biologicals, Aventis Pasteur MSD, Merck Vaccine Division), several universities in Europe, and other institutions.

The VHPB has strict operational and scientific independence. The VHPB Executive Secretariat also benefits from being located at the Department of Epidemiology and Social Medicine of the University of Antwerpen, Belgium, where it has the infrastructure and administrative services at its disposal.

Viral Hepatitis is produced and published by VHPB - Scientific editor: Guido François; Editor and copywriter: Diana Steimle - Photogravure made by Ability Design, Antwerpen, Belgium. Printed by WILDA, Antwerpen, Belgium.

For further information, please contact:

VHPB Executive Secretariat

Centre for the Evaluation of Vaccination

WHO Collaborating Centre for Prevention and Control of Viral Hepatitis

Department of Epidemiology and Social Medicine

University of Antwerpen

Universiteitsplein 1

B-2610 Antwerpen, Belgium

Tel 32 (0)3 8202523 Fax $32(0) 38202640$

E-mail: emmy.engelen@ua.ac.be

http://www.vhpb.org 